\title{
Utility of an Automated Thermal-Based Approach for Monitoring Evapotranspiration
}

\author{
Wim J. TIMMERMANS ${ }^{1}$, William P. KUSTAS ${ }^{2}$, and Ana ANDREU \\ ${ }^{1}$ University of Twente, Faculty of Geo-information Science and Earth Observation, \\ Department of Water Resources, Enschede, The Netherlands; \\ e-mail: w.j.timmermans@utwente.nl \\ ${ }^{2}$ Hydrology and Remote Sensing Laboratory, USDA/ARS, Beltsville, MD, USA \\ ${ }^{3}$ Instituto de Investigación y Formación Agraria y Pesquera (IFAPA), \\ Cordoba, Spain
}

\begin{abstract}
A very simple remote sensing-based model for water use monitoring is presented. The model acronym DATTUTDUT (Deriving Atmosphere Turbulent Transport Useful To Dummies Using Temperature) is a Dutch word which loosely translates as "it's unbelievable that it works". DATTUTDUT is fully automated and only requires a surface temperature map, making it simple to use and providing a rapid estimate of spatially-distributed fluxes. The algorithm is first tested over a range of environmental and land-cover conditions using data from four short-term field experiments and then evaluated over a growing season in an agricultural region. Flux model output is in satisfactory agreement with observations and established remote sensing-based models, except under dry and partial canopy cover conditions. This suggests that DATTUTDUT has utility in identifying relative water use and as an operational tool providing initial estimates of $E T$ anomalies in data-poor regions that would be confirmed using more robust modeling techniques.
\end{abstract}

Key words: remote sensing, water use monitoring, temperature index scheme, automated, operational. 


\section{INTRODUCTION}

Knowledge of the surface energy balance is of prime interest to the fields of meteorology, hydrology, and agronomy. Examples range from General Circulation Models (GCMs) for weather prediction and climate change to impacts of water use in threatened ecosystems, as well as the determination of crop water use, stress, and yield in agro-ecosystems. Numerous Soil-Vegetation-Atmosphere Transfer (SVAT) schemes have been developed in recent years with varying complexity. However, complex model parameterization is rarely possible at appropriate spatial or temporal resolution to adequately represent regional or global scale turbulent heat exchange (Goetz et al. 1999). Moreover, operational models for evapotranspiration (ET) estimation, using ground-based observations, have shown varying degrees of success (Parlange et al. 1995).

Satellite remote sensing potentially offers the possibility of collecting input data at a suitable temporal and spatial scale for regional applications. However, satellite observations cannot provide spatially distributed atmospheric variables, often required by SVAT schemes. These inputs include solar radiation, wind speed, air temperature, and vapor pressure over large heterogeneous areas (Jiang and Islam 2001). Consequently, several studies have proposed the combined use of remotely sensed with SVAT approaches that require minimal ground data (Anderson et al. 1997, Bastiaanssen et al. 1998, Norman et al. 1995, Roerink et al. 2000, Senay et al. 2013, Su 2002) or derive key meteorological data from the remotely sensed observations (Prihodko and Goward 1997, Prince et al. 1998). Generally, the surface energy balance equation is used to estimate actual evapotranspiration as a residual term (Jiang and Islam 2001). However, reliable estimation of surface energy balance components from remotely sensed observations typically requires land cover information about surface properties (i.e., land use/vegetation type, surface roughness, fractional vegetation cover) and a physicallybased SVAT scheme having land surface parameterization of the turbulent energy exchange. For operational use of these models, generally a fair degree of model expertise by the operator is needed as well.

Table 1 lists the input parameters and model user expertise on decisions that are necessary to apply the Two-Source Energy Balance (TSEB) model (Norman et al. 1995) and related Atmosphere Land Exchange Inverse (ALEXI) approach (Anderson et al. 1997, 2005), the Surface Energy Balance System (SEBS) model (Su 2002), the Surface Energy Balance Algorithm for Land (SEBAL) model (Bastiaanssen et al. 1998) and the Simplified Surface Energy Balance for operational applications (SSEBop) model (Senay et al. 2013) as compared to the current algorithm, DATTUTDUT. The table lists the main model inputs required by the differ- 
ent models, although sensitivity to these inputs significantly varies. For example, only nominal estimates of the meteorological input (wind speed, air temperature, and relative humidity) listed under the SEBAL algorithm are needed; the algorithm's internal calibration process circumvents the need for accurate values. Similarly for the NDVI end-member selection for the TSEB and SEBS models is one of a number of possible methodologies used in determining fractional vegetation cover (Carlson and Ripley 1997, Choudhury et al. 1994).

Table 1

Main model input required by

TSEB, ALEXI, SEBS, SEBAL, SSEBop, and DATTUTDUT

\begin{tabular}{|c|c|c|c|c|c|c|}
\hline Necessary input & TSEB & ALEXI & SEBS & SEBAL & SSEBop & \begin{tabular}{|c|} 
DATTU- \\
TDUT \\
\end{tabular} \\
\hline \multicolumn{7}{|l|}{ In situ / Ancillary data: } \\
\hline Solar radiation, or: & $\sqrt{ }$ & $\sqrt{ }$ & $\sqrt{ }$ & $\sqrt{ }$ & & \\
\hline Atmospheric transmittance, or & $\sqrt{ }$ & $\sqrt{ }$ & $\sqrt{ }$ & $\sqrt{ }$ & & \\
\hline Elevation & & & & & $\sqrt{ }$ & \\
\hline Atmospheric pressure & $\sqrt{ }$ & & $\sqrt{ }$ & & & \\
\hline Wind speed & $\sqrt{ }$ & $\sqrt{ }$ & $\sqrt{ }$ & $\sqrt{ }$ & & \\
\hline Air temperature & $\sqrt{ }$ & & $\sqrt{ }$ & $\sqrt{ }$ & $\sqrt{ }$ & \\
\hline Relative humidity & $\sqrt{ }$ & & $\sqrt{ }$ & $\sqrt{ }$ & & \\
\hline Sensor viewing angle & $\sqrt{ }$ & $\sqrt{ }$ & & & & \\
\hline Radiosounding & & $\sqrt{ }$ & & & & \\
\hline Reference $E T$ & & & & & $\sqrt{ }$ & \\
\hline \multicolumn{7}{|l|}{ Remote sensing / Spatial data: } \\
\hline Reflectance & & & $\sqrt{ }$ & $\sqrt{ }$ & $\sqrt{ }$ & \\
\hline NDVI/LAI & $\sqrt{ }$ & $\sqrt{ }$ & $\sqrt{ }$ & $\sqrt{ }$ & $\sqrt{ }$ & \\
\hline Surface temperature & $\sqrt{ }$ & $\sqrt{ }$ & $\sqrt{ }$ & $\sqrt{ }$ & $\sqrt{ }$ & $\sqrt{ }$ \\
\hline Landcover, or: & $\sqrt{ }$ & $\sqrt{ }$ & & & & \\
\hline Aerodynamic properties & $\sqrt{ }$ & $\sqrt{ }$ & $\sqrt{ }$ & & & \\
\hline \multicolumn{7}{|l|}{ User expertise: } \\
\hline Wet pixel selection & & & & $\sqrt{ }$ & & \\
\hline Dry pixel selection & & & & $\sqrt{ }$ & & \\
\hline NDVI end-member bare soil & $\sqrt{ }$ & & $\sqrt{ }$ & & & \\
\hline $\begin{array}{l}\text { NDVI end-member full } \\
\text { vegetation }\end{array}$ & $\sqrt{ }$ & & $\sqrt{ }$ & & & \\
\hline
\end{tabular}


In general, the more complex the model formulations of the land surfaceatmosphere exchange, the more information/input variables are required. With reliable inputs, often the more sophisticated models provide more reliable estimates under a wider range of environmental conditions. However, when monitoring over regions having little ground information or ancillary observations of meteorological conditions, the inputs required by more sophisticated models are not available or unreliable, causing significant uncertainty in model output. Under such conditions, a simple modeling approach requiring minimal ancillary inputs could prove to be fairly robust, particularly for long-term water use monitoring where errors in short-term (daily) ET are often modulated, for example when evaluated as cumulative $E T$ over a growing season. This is the rationale for developing a very simple model for routine monitoring of the surface energy balance, with emphasis on an operational system requiring no user expertise. The "Deriving Atmosphere Turbulent Transport Useful To Dummies Using Temperature (DATTUTDUT)" algorithm does not need any ancillary data and only requires a surface temperature image. Furthermore, the algorithm in theory does not need any user inference and is fully automated, provided a cloud-free and atmospherically corrected radiometric surface temperature image is available.

The main objective of this paper is to present an operational and automated remote sensing-based system requiring no calibration and suitable for monitoring spatially distributed water and heat fluxes and demonstrate advantages and limitations of using a very simple temperature-based approach. In Section 2, the formulations and their physical basis are presented and justification for simplifications is discussed. Then, in Section 3, the performance of the proposed model is analyzed. Three different comparison protocols are followed to demonstrate different aspects of the models utility. First the ability of reproducing local energy fluxes in relation to results from wellestablished and more complex remote sensing-based modeling schemes over a range of environmental and climatologic conditions is presented. Secondly, a spatial model inter-comparison over a very heterogeneous area is carried out to evaluate extreme conditions and performance across a landscape. A third, temporal, evaluation then concerns the performance in estimating actual evapotranspiration over a growing season. In Section 4 a discussion of the results of the different evaluations follows, after which the concluding remarks are provided in Section 5. The validation data for the evaluations come from large scale interdisciplinary experiments conducted in a semi-arid rangeland region - Monsoon'90 (Kustas et al. 1994a), a winter wheat/ grazing-lands site - Southern Great Plains'97 (Jackson et al. 1999), a corn and soybean production region - SMEX/SMACEX'02 (Kustas et al. 2005), an agricultural test site - REFLEX'12 (Timmermans et al. 2014), and an irri- 
gated agricultural site within an arid region - Gediz'98 (Kite and Droogers 2000).

\section{MODEL FORMULATION}

\subsection{Instantaneous fluxes}

Generally, remote sensing-based SVAT schemes use instantaneous observations of the land surface to provide estimates of instantaneous net radiation, $R_{N}$, soil, $G$, sensible, $H$, and latent, $\lambda E$, heat fluxes (all in $\mathrm{W} \mathrm{m}^{-2}$ ) by solving the energy balance equation

$$
R_{N}=G+H+\lambda E,
$$

where $\lambda$ represents the latent heat of vaporization $\left[\mathrm{J} \mathrm{kg}^{-1}\right]$ and $E$ is the amount of evaporated water $[\mathrm{kg}]$. The net radiation is usually estimated by dividing it into its components:

$$
R_{N}=R_{S}^{\downarrow}+R_{S}^{\uparrow}+R_{L}^{\downarrow}+R_{L}^{\uparrow}=\left(1-\rho_{0}\right) \cdot R_{S}^{\downarrow}+\varepsilon_{0} \cdot \varepsilon_{a} \cdot \sigma \cdot T_{a}^{4}-\varepsilon_{0} \cdot \sigma \cdot T_{0}^{4},
$$

where $R$ stands for radiation, and the subscripts $N, S$, and $L$ refer to net, shortwave, and longwave, and the superscripted arrows indicate incoming (downward) and outgoing (upward) flux directions. Temperature $(K)$ is represented by $T$, whereas the Greek symbols $\rho, \varepsilon$, and $\sigma$ represent albedo (-), emissivity (-), and the Stefan-Boltzmann constant $\left(5.6697 \times 10^{-8} \mathrm{~W} \mathrm{~m}^{-2} \mathrm{~K}^{-4}\right)$, respectively. Subscripts 0 and $a$ refer to surface and atmospheric level. Typically in these SVAT schemes the soil heat flux is estimated as a semiempirical ratio to net radiation, using a constant ratio or a function of vegetation indices (Bateni et al. 2014). The available energy, $R_{N^{-}} G$, is then distributed over the turbulent fluxes, $H$ and $\lambda E$, by either using the radiometric surface temperature to calculate $H$ and then obtain $\lambda E$ as a residual of the energy balance equation (Bastiaanssen et al. 1998, Norman et al. 1995, Su 2002), or by incorporating the effect of vapor pressure deficit to estimate crop water use or a stress index (Jackson et al. 1981, Menenti and Choudhury 1993).

In the current approach we attempt to solve Eqs. 1 and 2 in an automated manner by parameterizing all variables using only $T_{0}$ and its end-members, $T_{\min }$ and $T_{\max }$ as an input. These temperature extremes are derived from the image itself, which should be cloud free and have constant atmospheric conditions.

The surface albedo has been reported to vary with surface temperature depending on moisture conditions by several authors (Bastiaanssen et al. 1998, Jacob et al. 2002). Other approaches assume nominal values for soil and vegetation reflective properties (French et al. 2003, Kustas and Norman 
1999). Here, the surface albedo is thought to vary linearly with radiometric surface temperature between 0.05 and 0.25 , following

$$
\rho_{0}=0.05+\left(\frac{T_{0}-T_{\min }}{T_{\max }-T_{\min }}\right) \cdot 0.2 .
$$

These somewhat arbitrary values are taken from Brutsaert (1982) and Garratt (1992); the basic assumption is that dark densely vegetated objects appear cooler and bright bare objects such as soils and rock outcrops generally appear hot.

The shortwave incoming radiation follows from

$$
R_{S}^{\downarrow}=\tau \cdot S_{\text {exo }},
$$

where $\tau$ represents the shortwave atmospheric transmissivity [-] and $S_{\text {exo }}$ $\left[\mathrm{W} \mathrm{m}^{-2}\right]$ is the exo-atmospheric shortwave radiation which depends only on the sun-earth geometry (Campbell and Norman 1998, Monteith and Unsworth 1990).

To facilitate a fully automatic and fast operational scheme, nominal values are taken for transmissivity and emissivity values. For clear sky conditions, Burridge and Gadd (1974) presented a very simple parameterization for instantaneous shortwave atmospheric transmissivity [-], following

$$
\tau=0.6+0.2 \cdot \sin (\alpha),
$$

where $\alpha$ represents the solar elevation angle [rad], useful when dealing with large image scenes where solar angles are not constant. However, for simplicity here a constant value of 0.7 is taken for the atmospheric transmissivity. Numerous empirical relations are reported for apparent atmospheric emissivity (Brutsaert 1982). If the following, approximation of Bastiaanssen et al. (1998) is adopted

$$
\varepsilon_{a}=1.08 \cdot(-\ln \tau)^{0.265}
$$

and, in combination with an atmospheric transmissivity of 0.7 , an apparent atmospheric emissivity of about 0.8 is obtained. Since most natural objects emit radiation at least at an efficiency of $96 \%$ (Garratt 1992) the surface emissivity $[-]$ is taken equal to unity. Taking the air temperature equal to $T_{\min }$ in combination with these nominal values for emissivity, all radiation components can now be determined following Eq. 2.

The ratio between soil heat flux and net radiation, $G[-]$, is reported to vary from 0.05 for fully vegetated areas (Choudhury 1987, Monteith and Unsworth 1990) to 0.45 for bare soil (Brutsaert 1982, Choudhury 1987). In a 
similar fashion as for the surface albedo, a linear relation with radiometric surface temperature is assumed:

$$
\Gamma=\frac{G}{R_{n}}=0.05+\left(\frac{T_{0}-T_{\min }}{T_{\max }-T_{\min }}\right) \cdot 0.4 .
$$

The underlying assumption is again that dark densely vegetated areas appear cooler (Bastiaanssen et al. 1998, Menenti and Choudhury 1993, Roerink et al. 2000) and over densely vegetated areas a smaller part of the net radiation is reaching the surface. Bare soil generally appears hotter and over these areas a larger part of the net radiation will be available to heat the soil surface.

A common feature of thermal-based methods is that radiometric surface temperature is the key remotely-sensed parameter partitioning the available energy between sensible and latent heat. This is also reflected in several sensitivity studies (Anderson et al. 1997, Bastiaanssen 1995, Kustas and Norman 1999) and especially in model inter-comparisons (Zhan et al. 1996) where surface temperature clearly is the input variable that has the largest impact on model output. It is also important to note that surface layer air temperature is also a critical variable for many of the models that require a surface-air temperature gradient unless there is a built-in procedure that removes or minimizes this requirement (Anderson et al. 2007, Timmermans et al. 2007). A modeling framework that minimizes the effect of errors in surface and surface layer air temperatures on the calculation of the turbulent fluxes was proposed by Bastiaanssen et al. (1998). Their methodology, SEBAL, basically assumes linearity between surface-air temperature differences and surface temperature whose slope is defined by dry and wet areas (hydrologic extremes or end-members) within the scene having maximum and minimum surface temperatures and heat fluxes, $H$ and $L E$, determined from the energy balance equation (Eq. 1). When evaluating such a technique, along with other traditional remote sensing-based SVAT models, French et al. (2005b) and Timmermans et al. (2007) found that the linearity assumption in the SEBAL scheme is not universally valid, a phenomenon also recognized by Bastiaanssen et al. (1998) in their original paper. However, this relation has utility in providing an internal calibration for effectively partitioning the available energy between $H$ and $L E$ over the scene as long as there is no significant land cover differences (i.e., agricultural versus forested areas) within the scene which would have a major impact of aerodynamic properties (Norman et al. 2006). In SEBAL the assumption is made that at a certain maximum radiometric surface temperature the latent heat flux is zero, whereas sensible heat flux is at its minimum rate at a certain minimum radiometric surface temperature. However, instead of using flux inversion at the 
extremes which requires iterative processes to determine the resistance-heat flux relation, here a simple linear relation between evaporative fraction $(\Lambda)$ and surface temperature extremes is assumed:

$$
\Lambda=\frac{\lambda E}{\lambda E+H}=\frac{\lambda E}{R_{n}-G}=\frac{T_{\max }-T_{0}}{T_{\max }-T_{\min }} .
$$

There needs to be hydrological contrast in the image, meaning that both the wet and dry conditions are present in the image scene; a necessary condition for methods that are trying to derive the turbulent fluxes from hydrological contrast (Bastiaanssen et al. 1998, Menenti and Choudhury 1993, Pelgrum and Bastiaanssen 1996, Roerink et al. 2000). The maximum temperature, $T_{\max }$, is taken as the hottest pixel in the image, whereas the minimum temperature, $T_{\min }[\mathrm{K}]$, is taken as the $0.5 \%$ lowest temperature in the image. The reason for not taking the lowest temperature in the image is to avoid extreme conditions (open water) and to take that part of the image that is transpiring at a potential rate. Following Tasumi et al. (2000), the hottest location in the image is used to determine $T_{\max }$ in Eq. 8. Similar approaches based on the same physical principle have been proposed since the early days of operational thermal infrared remote sensing (Jackson et al. 1981, Jiang and Islam 2001, Roerink et al. 2000). However, the main differences with the current approach are that DATTUTDUT is tuning-free, fully automated, and only requires an LST image as input.

\subsection{Daily estimates}

Extending essentially instantaneous fluxes from a satellite "snapshot" observation to daily values either involves multi-temporal observations such as from geostationary satellite observations (Anderson et al. 1997, Mecikalski et al. 1999, Norman et al. 2000) or assuming a constant energy partitioning over the daytime period. By assuming self-preservation (conservative relative partition of the energy flux among its components) in the diurnal evolution of the energy balance, $\Lambda$ can be taken as constant throughout the day. It has been demonstrated that this assumption holds for environmental conditions where soil moisture does not change significantly (Crago 1996, Kustas et al. 1994b, Nichols and Cuenca 1993, Shuttleworth et al. 1989). This assumption is also used in other models, such as SEBAL (Bastiaanssen et al. 1998) and S-SEBI (Roerink et al. 2000).

Since geostationary satellites only provide useful data for mid-latitudes at a rather low spatial resolution $(\sim 5-10 \mathrm{~km})$ and also because of a need for a simplified approach, hence minimum computational requirements, here the assumption of constant evaporative fraction over the daytime period is adopted. However, the recent work has shown that this assumption might be 
violated under certain conditions (Chehbouni et al. 2008, Delogu et al. 2012, Gentine et al. 2007) and a recent study suggests using at-surface solar radiation is the most robust for up-scaling instantaneous ET over a range of environmental conditions (Cammalleri et al. 2014). Nevertheless, this approach provides reasonable estimation of daily amounts of evapotranspiration from the instantaneous estimates during the daytime (Brutsaert and Chen 1996).

Since the evaporative fraction is estimated from Eq. 8 and the soil heat flux is assumed to cancel on a daily basis, one only needs an estimate of the daily amount of net radiation to obtain the daily amount of latent heat, $\lambda E_{24}$, both in $\mathrm{MJ} \mathrm{m}^{-2}$;

$$
\Lambda_{i}=\Lambda_{24}=\frac{\lambda E_{i}}{\lambda E_{i}+H_{i}}=\frac{\lambda E_{24}}{\lambda E_{24}+H_{24}}=\frac{\lambda E_{24}}{R_{n, 24}-G_{24}}=\frac{\lambda E_{24}}{R_{n, 24}} .
$$

The daily amount of net radiation $R_{n, 24}\left[\mathrm{MJ} \mathrm{m}^{-2}\right]$ is calculated following:

$$
R_{n, 24}=S_{n, 24}+L_{n, 24},
$$

where $S$ and $L$ represent shortwave and longwave radiation, whereas the subscripts $n$ and 24 stand for net and 24 hours, respectively. Several methods exist for estimating both components. Here the daily shortwave radiation $[\mathrm{MJ}]$ is estimated following:

$$
S_{n, 24}=\left(1-\rho_{0,24}\right) \cdot \tau_{24} \cdot S_{\text {exo }, 24},
$$

where the daily exo-atmospheric radiation $\left[\mathrm{MJ} \mathrm{m}^{-2}\right], S_{\text {exo,24 }}$, depends only on trigonometric astronomic relations, readily available from handbooks (Campbell and Norman 1998, Duffie and Beckman 1991, Monteith and Unsworth 1990) or by integrating the exo-atmospheric radiation from sunrise to sunset. Daily average surface albedo, $\rho_{0,24}$, is obtained from multiplying the instantaneous value with a constant $c[-]$. According to Menenti et al. (1989) $c$ may be taken equal to 1.1 when compared to typical daytime surface albedo values. Daily average transmissivity values $[-], \tau_{24}$, may be obtained from several sources. Here we adopted the instantaneous value under the assumption of a cloud free day.

For the longwave components a semi-empirical relation developed by de Bruin (1987) for daily average net longwave radiation, $L_{n, 24-\text { avg }}\left[\mathrm{W} \mathrm{m}^{-2}\right]$, is used:

$$
L_{n, 24-\text { avg }}=-110 \cdot \tau_{24} .
$$

To convert this quantity to daily net longwave radiation, in $\mathrm{MJ} \mathrm{m}^{-2}$, it needs to be multiplied with the daylength (s). The daily net longwave radiation is assumed constant over the scene. 
In order to obtain daily amounts of water evaporated and transpired, $E_{24}$ $\left[\mathrm{kg} \mathrm{m}^{-2}\right]$, the daily total of latent heat, $\lambda E_{24}$, needs be corrected for the latent heat of vaporization, $\lambda\left[\mathrm{MJ} \mathrm{kg}^{-1}\right]$. This latent heat of vaporization depends to some extent on air temperature, for which $T_{\min }$ is taken:

$$
\lambda=2.501-0.002361 \cdot\left(T_{\min }-273.15\right) \text {. }
$$

Although we developed the scheme to be fully automated and also such that no ancillary data is needed, it is obvious that if additional data are available these may be applied accordingly. Since the algorithm is physically based, use of these ancillary data should potentially further improve the algorithm performance.

\section{MODEL PERFORMANCE}

To demonstrate different aspects of the models' utility, three different comparison protocols are followed. First, the ability of estimating local energy fluxes is presented. In order to ensure both a range of environmental and climatic conditions as well as sufficient ground truth data, four study areas having extensive field observations were selected for evaluating DATTUTDUT output and to compare results with published results using more established and more complex remote sensing-based energy balance models (French et al. 2005b, Timmermans et al. 2007, 2014). The other remote sensing energy balance modeling approaches applied to these data sets are SEBAL as originally formulated in Bastiaanssen et al. (1998) and two versions of the TSEB (Norman et al. 1995). One version uses local meteorological observations (French et al. 2003, Kustas and Norman 1997) and was applied to the Monsoon'90, SGP'97, and REFLEX'12 experiments. The other version, ALEXI, is a time-integrated approach with TSEB coupled to an atmospheric boundary layer growth model and requiring thermal-IR observations at two instances in the early and mid-morning period (Anderson et al. 1997, French et al. 2005b) and was applied to the SMACEX'02 experimental site.

Secondly, a spatial model inter-comparison between DATTUTDUT and the SEBAL and TSEB algorithms over a very heterogeneous area is carried out to evaluate extreme conditions and model performance across a landscape. Data from the REFLEX'12 experiment (Timmermans et al. 2014) over an agricultural test-site near Barrax, Spain, is used here since the area is characterized by the co-existence of dry and hot bare soil and a variety of well-watered crops.

Thirdly, with a fully automated algorithm using midday surface temperature that does not require ancillary data on land use, fractional vegetation cover or meteorological inputs, just hydrological extremes (wet and dry pix- 
el) within the scene for estimating surface energy balance, the challenge remains to demonstrate its utility for operational monitoring of longer-term water use. This is done by applying the scheme to data collected at two sites during the joint International Water Management Institute (IWMI)/General Directorate of Rural Services, Government of Turkey (GDRS) study of the Gediz River Basin, as described in Kite and Droogers (2000). The DATTUTDUT algorithm is evaluated against published results from other methodologies. However, in this case the purpose is to evaluate its utility for operational water use monitoring purposes.

\subsection{Data description}

\section{Monsoon'90}

The Monsoon'90 field experiment is described in Kustas et al. (1994a), and covers a semiarid rangeland in the Walnut Gulch Experimental Watershed near Tucson, Arizona. The remote sensing data used in this analysis were acquired with the NS001 sensor mounted in a NASA C-130 aircraft. The NS001 instrument has eight bands, of which seven correspond to the Landsat Thematic Mapper instrument. This provided aircraft-based VIS, NIR, and TIR measurements from three days during early August 1990 are used, representing dry (DOY 213), intermediate (DOY 221), and wet (DOY 216) conditions. Land cover data, necessary for the TSEB algorithm, was taken from classifying Landsat TM data of September 1990. A detailed description of the dataset used is provided in Humes et al. (1994), with the note that here data from DOY 213 is used instead of the data from DOY 209 used in that particular study. There were eight flux tower sites distributed over the watershed covering the main land cover types. Details of the tower measurements are given in Kustas et al. (1994a).

\section{SGP'97}

The Southern Great Plains'97 (SGP'97) experiment is summarized by Jackson et al. (1999). The data set included VIS, NIR, and TIR remote measurements over the EL Reno, Oklahoma, site and comprised fallow and tilled winter wheat and grassland/pasture fields. Data collected were from the Thermal Infrared Multi-spectral Scanner (TIMS) and the Thematic Mapper Simulator (TMS) airborne instruments. Data from two days during the summer of 1997, representing wet (DOY 180) and dry (DOY 183) conditions, are used at a spatial resolution of $15 \mathrm{~m}$, covering agricultural fields (both bare and vegetated) and natural riparian areas. The land use data originates from $30 \mathrm{~m}$ resolution imagery, based on the combination of known ground conditions and Landsat TM imagery from DOY 205 that same year. Details of the processing of the remote sensing imagery can be found in 
French et al. (2003). There were four flux towers covering the main land cover types. Details of the tower measurements are given in Twine et al. (2000).

\section{SMACEX'02}

The Soil Moisture Atmosphere Coupling Experiment 2002 (SMACEX'02) data set described by Kustas et al. (2005) was collected over an experimental watershed in central Iowa, USA, an upper Midwest corn and soybean production region. The experiment took place during the 2002 growing season. An ASTER image collected on DOY 182 (1 July 2002) was used. The landcover map was derived from a supervised classification of Landsat imagery and ground truth observations carried out in June and July. Flux tower measurements were available from 10 locations distributed over the study area to obtain representative areal sampling (Prueger et al. 2005).

\section{REFLEX'12}

The REFLEX'12 campaign was an airborne campaign to support the understanding of land-atmosphere interaction processes (Timmermans et al. 2014). The experiment was carried out over the Las Tiesas Experimental Farm test site near Barrax in the La Mancha region in Spain, maintained by the Provincial Technical Agronomical Institute (ITAP). The campaign took place during 10 days in the end of July 2012, when the non-irrigated parts of the area are characterized by extremely dry conditions. Airborne imagery from the Airborne Hyperspectral Sensor (AHS) obtained during DOY 207 (de Miguel et al. 2015) was used in this analysis. Flux tower observations and a Large Aperture Scintillometer (LAS) covering four sites with distinctly different landcover provided the ground truth (van der Tol et al. 2014).

\section{GEDIZ'98}

The intercomparison study over an irrigated area in the Gediz River Basin in Western Turkey is described in detail in Kite and Droogers (2000). For the analysis used here a total of 73 level-1B NOAA-AVHRR images were downloaded from the internet and pre-processed into surface reflectance and surface temperature images. The procedures followed are described in detail in Gieske and Meijninger (2005). Flux observations were available from two locations within the study region. A Large Aperture Scintillometer (LAS) was deployed over a valley in the Gediz River Basin in Western Turkey. The pathlength of the scintillometer was $2.7 \mathrm{~km}$ and provided surface fluxes at a scale comparable to the AVHRR imagery. The land use in the valley was heterogeneous, consisting of $60 \%$ of raison grape, $15 \%$ cotton, $15 \%$ of fruit trees, $5 \%$ pasture, and $5 \%$ of mixed tree species. The second location con- 
sisted of an irrigated cotton field, located west of Menemen, in a cotton production region, homogeneous at the AVHRR pixel scale. Fluxes at this location were obtained from a fast-response temperature sensor using the temperature variance method (de Bruin 1994). In addition, net radiation, soil heat flux, and additional meteorological measurements were obtained at this location (Meijninger and de Bruin 2000).

\subsection{Local model evaluation versus ground observations}

The main assumption in the current algorithm concerns the linearity between "instantaneous" scaled temperature and half-hourly evaporative fraction via Eq. 8. The datasets described above provided the opportunity to validate that assumption. In Figure 1 the observed evaporative fraction $(\Lambda)$ is plotted versus the scaled temperature, as defined in Eq. 8 for all four experiments. The RMSD-value (see Table 2 for definition) between the observations and model estimates for the four experiments is approximately 0.13 . A linear regression with an $R^{2}$ equal to 0.65 (0.81 and 0.62 for TSEB and SEBAL, respectively) was found with a slope of $0.71(0.98$ and 0.79 for TSEB and SEBAL, respectively) and an intercept of 0.22 (0.02 and 0.10 for TSEB and SEBAL, respectively). A slope close to unity with a small intercept provides support for the use of Eq. 8 for these landscapes. Note that there was no model tuning in applying the DATTUTDUT algorithm.

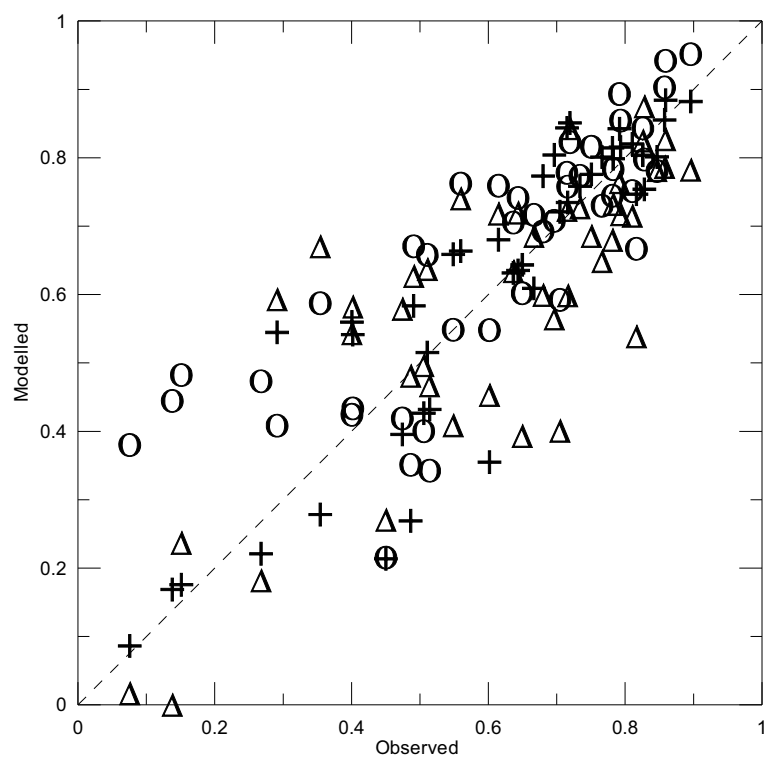

Fig. 1. Observed versus modeled evaporative fraction for all four experiments, using DATTUTDUT $(\mathrm{O}), \operatorname{SEBAL}(\Delta)$, and TSEB $(+)$. 
The scatter between DATTUTDUT-derived $\Lambda$ and observations increases significantly with increasing dry or stressed conditions (i.e., lower $\Lambda$ values). On the other hand, the trend for SEBAL is a relatively large dispersion around intermediate values of $\Lambda$, whereas this is less so with the TSEB approach. The extremely stressed cases $(\Lambda<0.3)$ originate from sites in the REFLEX'12 dataset which were sparsely vegetated. Removing these observations from the analysis for the DATTUTDUT model resulted in a minor increase in $R^{2}$ from 0.65 to 0.68 . However, more importantly, the slope and intercept changed from 0.71 and 0.22 to 0.94 and 0.06 , respectively. While the REFLEX'12 conditions may be considered rather extreme in terms of vegetation stress and heterogeneity in canopy cover, reliable estimates under such conditions are necessary for accurately monitoring the spatial and temporal variations in fluxes across many landscapes.

The results for the four energy balance components for the three models are illustrated in Fig. 2 and performance of the models is evaluated using difference statistics by Willmott (1984). Table 2 lists the definitions and the quantities of the various difference statistics for the surface energy balance components as well as for the evaporative fraction. These include the RMSD, the mean absolute difference (MAD), and the mean absolute percent difference (MAPD). There is no distinction made between the four experimental datasets, and the figure indicates that the scatter with the measurements is generally greater with DATTUTDUT and SEBAL than with TSEB. In particular, the net radiation estimates of the DATTUTDUT algorithm tend to have greater discrepancies with the observations, which are more prominent at the lower values. The mean difference between observation and prediction for $R_{N}$ were about 10 and $30 \mathrm{~W} \mathrm{~m}^{-2}$ for TSEB and SEBAL, respectively, and around $45 \mathrm{~W} \mathrm{~m}^{-2}$ for DATTUTDUT. With respect to the predicted soil heat fluxes, also the largest discrepancies with observations
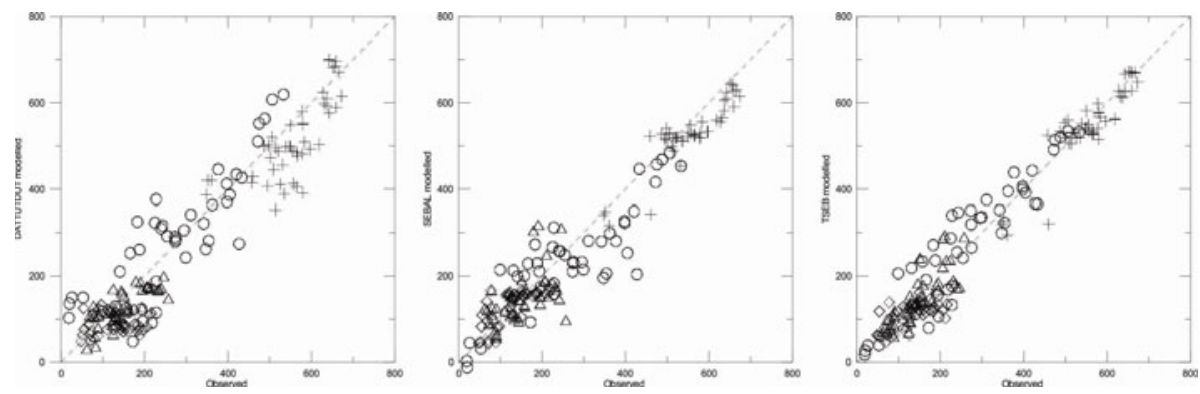

Fig. 2. Modeled and observed instantaneous energy balance components of $R n(+)$, $G(\diamond), H(\Delta)$, and $L E(\circ)$ in $\mathrm{W} \mathrm{m}^{-2}$ for the Monsoon'90 (DOY 213, 216, and 221), SGP'97 (DOY 180 and 183), SMACEX (DOY 182), and REFLEX'12 (DOY 207) sites, for the three models. 


\begin{tabular}{|c|c|c|c|c|c|c|c|c|c|}
\hline$\widehat{\ominus}$ & \multirow{3}{*}{$<$} & a & $\begin{array}{ll} & \overrightarrow{0} \\
\end{array}$ & $\begin{array}{l}6 \\
0 \\
0\end{array}$ & స్ & $\stackrel{\infty}{0}$ & $\stackrel{9}{9}$ & $=$ & $\frac{m}{0}$ \\
\hline 5 & & - & $\overrightarrow{6}$ & $\begin{array}{l}\text { ชै } \\
0\end{array}$ & ปे & 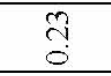 & 8 & 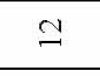 & $\frac{0}{0}$ \\
\hline 巨 & & $\Omega$ 㑏 & $\begin{array}{ll} & \overrightarrow{6} \\
\end{array}$ & ? & $\vec{\sim}$ & $\vec{\sim}$ & 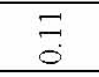 & $\infty$ & $\frac{J}{0}$ \\
\hline 造 & \multirow{3}{*}{ 过 } & A & 寸 & ๙ & $m$ & $\stackrel{8}{ \pm}$ & J & $\ddot{\imath}$ & $\stackrel{\infty}{\sim}$ \\
\hline $\bar{\Xi}$ & & - & 寸 & $\stackrel{\infty}{i}$ & m & $\stackrel{\text { I }}{工}$ & $\mathscr{v}$ & $\stackrel{0}{-}$ & in \\
\hline$\stackrel{\tilde{E}}{E}$ & & $\therefore$ 活 & 技 & $\stackrel{\text { In }}{d}$ & m & $\cong$ & $\overline{6}$ & ปี & 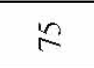 \\
\hline $\begin{array}{l}0 \\
\text { s } \\
\text { s }\end{array}$ & \multirow{3}{*}{$\mathbb{I}$} & A 寸 & 寸 寸 & $\stackrel{\infty}{\sim}$ & in & F & $m$ & $\widetilde{U}$ & ले \\
\hline$\tilde{\sigma}$ & & ー 寸 & 导 & 买 & $n$ & $\widetilde{6}$ & $\stackrel{0}{1}$ & $\stackrel{\infty}{\sim}$ & $m$ \\
\hline \& & & $\approx$ 寺 & 吉 & $\stackrel{\infty}{ \pm}$ & $n$ & $\ddot{n}$ & Y & $\stackrel{\infty}{\mathrm{N}}$ & in \\
\hline I & \multirow{3}{*}{10} & A & m & $\pi$ & F & $\overparen{\sim}$ & in & \& & छ \\
\hline 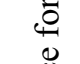 & & - J & ก & $\stackrel{m}{=}$ & F & in & 8 & 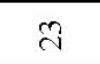 & f \\
\hline స్ & & 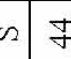 & กำ & $n$ & 8 & \& & $\stackrel{2}{2}$ & $\stackrel{2}{2}$ & $\bar{m}$ \\
\hline क्षे & \multirow{3}{*}{ 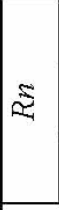 } & A & $\begin{array}{l}n \\
i n\end{array}$ & $\frac{0}{n}$ & $\bar{\infty}$ & ‡ & ชิ & 二 & $E$ \\
\hline$\frac{2}{0}$ & & -1 况 & $\begin{array}{l}\infty \\
n \\
n\end{array}$ & $\stackrel{\infty}{4}$ & $\bar{\infty}$ & 8 & $\stackrel{\infty}{\sim}$ & in & $m$ \\
\hline ఏ & & $\Omega$ 唔 & 号 & $\stackrel{\infty}{\sim}$ & $\bar{\infty}$ & $\approx$ & $\bar{m}$ & $r$ & $\stackrel{n}{7}$ \\
\hline 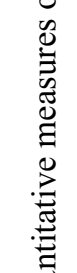 & 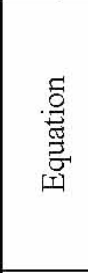 & & $\begin{array}{l}0 \\
=\sqrt{-1} \pi\end{array}$ & $=\underbrace{\infty}_{-1} \pi$ & 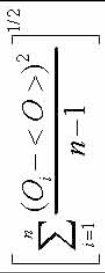 & 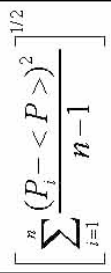 & $\begin{array}{l}\overline{0} \\
1 \\
=\overline{D_{1}} \\
=\sqrt{-1}=\end{array}$ & 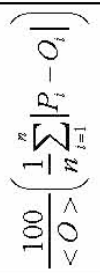 & 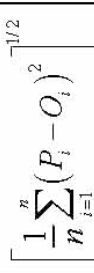 \\
\hline 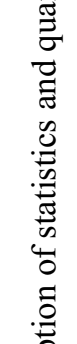 & 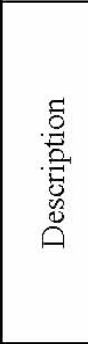 & 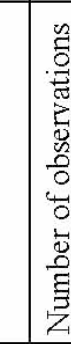 & 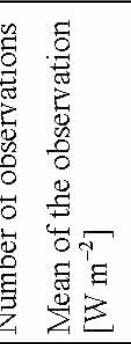 & 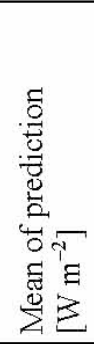 & 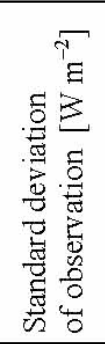 & 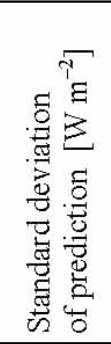 & 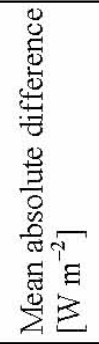 & 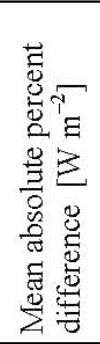 & 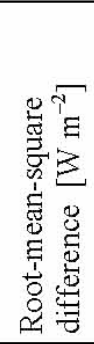 \\
\hline 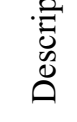 & 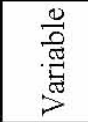 & 乙 & $\hat{\gamma}$ & $\hat{\mathrm{V}}$ & ஜ & कि & 恶 & 育 & $\sum_{\infty}^{\theta}$ \\
\hline
\end{tabular}


are noted for the DATTUTDUT scheme, an under-estimation of around $40 \mathrm{~W} \mathrm{~m}^{-2}$, partly because of its direct linkage with $R_{N}$. However, the main objective here is to demonstrate the utility of the current scheme for determining spatially distributed water and heat fluxes, which are governed by the amount of available energy, $R_{N}-G$. Since over- and under-estimations of $R_{N}$ and $G$ are generally paired, there is reasonable agreement in modeled and observed available energy.

Mean biases between observation and prediction for sensible heat flux were negligible for TSEB and SEBAL and nearly $20 \mathrm{Wm}^{-2}$ for the DATTUTDUT scheme. Biases in latent heat flux were lowest for TSEB $\left(\sim 15 \mathrm{~W} \mathrm{~m}^{-2}\right), 20 \mathrm{~W} \mathrm{~m}^{-2}$ for DATTUTDUT, and highest for SEBAL at $\sim 30 \mathrm{~W} \mathrm{~m}^{-2}$. The RMSD-values for the three models range from 35 to $55 \mathrm{~W} \mathrm{~m}^{-2}$ for $H$ and from 55 to $80 \mathrm{~W} \mathrm{~m}^{-2}$ for $\lambda E$. A point worth mentioning here is that significant energy balance closure gaps $\left(\sim 100 \mathrm{~W} \mathrm{~m}^{-2}\right)$ were sometimes evident in the flux tower data (Prueger et al. 2005, Twine et al. 2000, van der Tol et al. 2014). Although the measurements were corrected for lack of energy balance closure, following French et al. (2005a, b), the model-measurement differences do include the scatter attributed to uncertainty/energy balance closure errors in the flux observations.

The described predictions of $H$ and $\lambda E$ translate directly into $\Lambda$, and because of its relevance for the current approach the performance statistics for $\Lambda$ are shown in Table 2 as well. All three models show an almost perfect match between the mean observed and mean predicted value, where the discrepancy of DATTUTDUT is largest but still minimal at 4\%. This is mainly caused by the aforementioned deviations between observations and predictions of the turbulent fluxes at dry and sparsely vegetated locations. RMSDvalues for TSEB are 0.10, whereas SEBAL and DATTUTDUT show values of 0.14 and 0.13 , respectively.

\subsection{Spatial model evaluation}

The Barrax area is characterized by rather extreme conditions covering the full range in fractional vegetation cover as well as in moisture conditions, rendering sensible heat fluxes ranging from stable conditions to values as high as $400 \mathrm{~W} \mathrm{~m}^{-2}$ (Timmermans et al. 2008). Therefore, the REFLEX campaign offered an excellent opportunity to analyze spatial differences in model output.

Maps of model output for evaporative fraction are shown in the upper panels of Fig. 3 for TSEB, SEBAL, and DATTUTDUT. The patterns in evaporative fraction are similar for all three models. Spatial correlation between DAUTTUTDUT and TSEB is 0.92, between DATTUTDUT and SEBAL it is 0.40 , and between TSEB and SEBAL this equals 0.38 . The rela- 

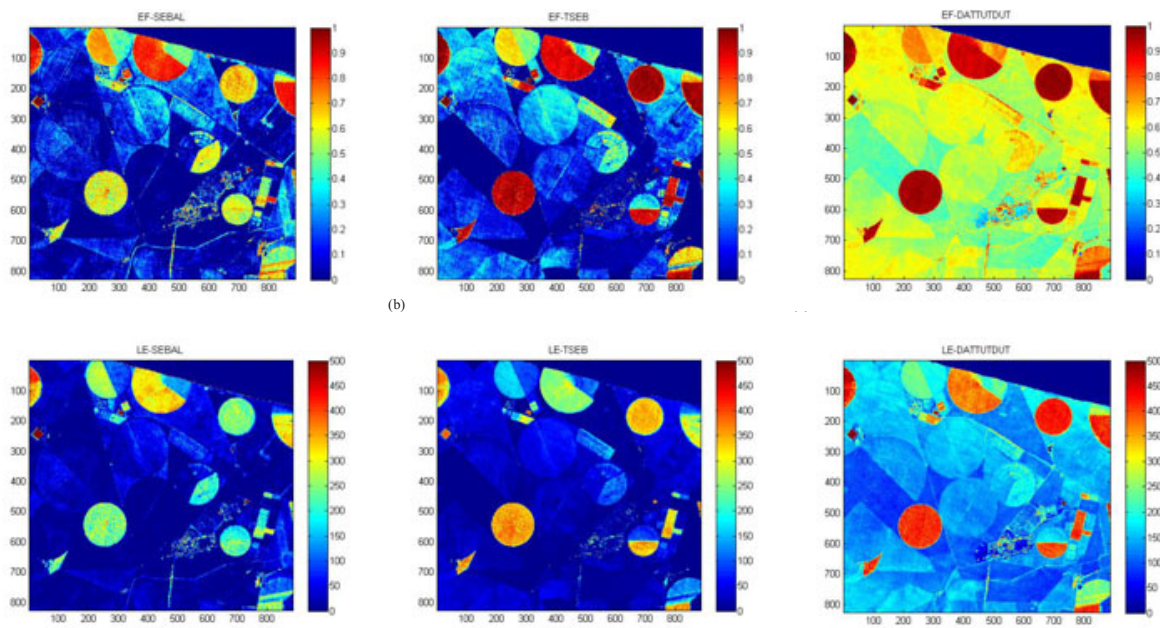

(e)

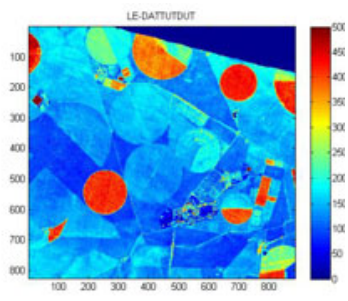

Fig. 3. Distribution of model output for $E F$ and $L E$ for all three models.

tively low correlation between SEBAL and TSEB is mainly caused by the difference in estimation of surface roughness length for momentum, as noted by Timmermans et al. (2007), and will not be discussed further here. The relatively high correlation between TSEB and DATTUTDUT is encouraging, given the simplicity of the latter. However, despite the rather good spatial agreement of evaporative fraction between the three models, especially between TSEB and DATTUTDUT, there are absolute differences of up to 0.50 [-] for some areas (see Table 3). How these translate into absolute values of latent heat flux is shown in the lower panels of Fig. 3; over certain areas differences of up to $150 \mathrm{~W} \mathrm{~m}^{-2}$ are noted. These are significant differences, similar to those reported by Timmermans et al. (2007) between SEBAL and TSEB model output of sensible heat flux.

For the relatively wet, thus irrigated, areas the three schemes show a rather similar response, which is also reflected in Table 3. For the drier, nonirrigated, parts of the area the DATTUTDUT scheme shows considerably higher values for $\Lambda$ as compared to SEBAL and TSEB. This is also reflected in Fig. 1, where the 4 driest observations originate from the REFLEX'12 campaign, over a vineyard, a wheat stubble field, a forest nursery, and a camelina field (Andreu et al. 2015). SEBAL and TSEB show reasonable to good performance for these sites versus observations, whereas the simple scheme has clear problems producing the proper output under these circumstances. Apart from the earlier-mentioned issue of not parameterizing the aerodynamic roughness effects by DATTUTDUT, which is especially noticed in dry and aerodynamically rough areas, another issue here is the high spatial resolution of the REFLEX'12 imagery in combination with the auto- 
Table 3

LST and evaporative fraction averaged for the main landcover units

\begin{tabular}{|l|c|c|r|r|c|c|}
\hline \multirow{2}{*}{\multicolumn{1}{|c|}{ Landcover }} & \multicolumn{2}{|c|}{ LST [K] } & \multicolumn{4}{c|}{ Evaporative fraction [-] } \\
\cline { 2 - 7 } & Avg. & St. dev. & SEBAL & TSEB & \multicolumn{2}{c|}{ DATTUTDUT } \\
\cline { 2 - 7 } & & & & Original & Adjusted \\
\hline Bare pasture & 315.9 & 2.7 & 0.09 & 0.01 & 0.49 & 0.00 \\
Barley stubble & 312.3 & 1.7 & 0.14 & 0.29 & 0.59 & 0.19 \\
Building & 312.4 & 6.3 & 0.08 & 0.08 & 0.59 & 0.19 \\
Camelina & 315.9 & 1.6 & -0.09 & 0.04 & 0.49 & -0.00 \\
Corn & 299.5 & 1.9 & 0.60 & 0.91 & 0.95 & 0.87 \\
Crops & 310.3 & 4.1 & 0.23 & 0.41 & 0.65 & 0.30 \\
Fallow land & 315.7 & 2.7 & 0.13 & 0.01 & 0.50 & 0.01 \\
Forest nursery & 314.7 & 1.7 & 0.21 & 0.04 & 0.53 & 0.06 \\
Grass & 301.8 & 2.7 & 0.57 & 0.89 & 0.88 & 0.74 \\
Harvested cropland & 312.3 & 1.9 & -0.08 & 0.20 & 0.59 & 0.19 \\
Open water & 296.9 & 5.0 & 0.95 & 1.07 & 1.02 & 1.00 \\
Orchard & 314.5 & 5.0 & 0.07 & 0.10 & 0.53 & 0.08 \\
Poppy & 309.2 & 2.1 & 0.63 & 0.51 & 0.68 & 0.35 \\
Sunflower & 301.4 & 3.6 & 0.78 & 0.84 & 0.89 & 0.76 \\
Vineyard & 312.8 & 1.8 & 0.13 & 0.06 & 0.58 & 0.16 \\
Wheat stubble & 313.1 & 1.3 & -0.07 & 0.20 & 0.57 & 0.15 \\
\hline
\end{tabular}

mated end-member selection, $T_{\min }$ and $T_{\max }$. The latter issue causes an increase in the sensitivity of DATTUTDUT to variability in the heat fluxes under dry conditions.

The spatial resolution equals $4.0 \mathrm{~m}$ and therefore a high within-field variation of land surface temperature is observed (Table 3). In addition, there is a large number of fields of different landcover that were dry and hot at the time of image acquisition. Consequently, the histogram distribution of LST, middle panel of Fig. 4, has an exceptionally long tail on the high end. Selecting the hottest pixel in the image to represent $T_{\max }$ in Eq. 8, under these conditions, results in a significant portion of the image yielding too high evaporative fraction estimates from DATTUTDUT.

It is beyond the scope of the current contribution to perform a detailed sensitivity analysis on the selection of the end-members in the line of Timmermans et al. (2007). However, in the LST histogram in Fig. 4 the absolute minimum $(0.0 \%)$ and maximum $(100.0 \%)$ are indicated as well as the 0.5 and $99.5 \%$ - minimum and maximum values of LST. The DATTUTDUT model uses the 0.5 and $100.0 \%$ values for $T_{\min }$ and $T_{\max }$, which are 297.6 and $333.7 \mathrm{~K}$, respectively. 

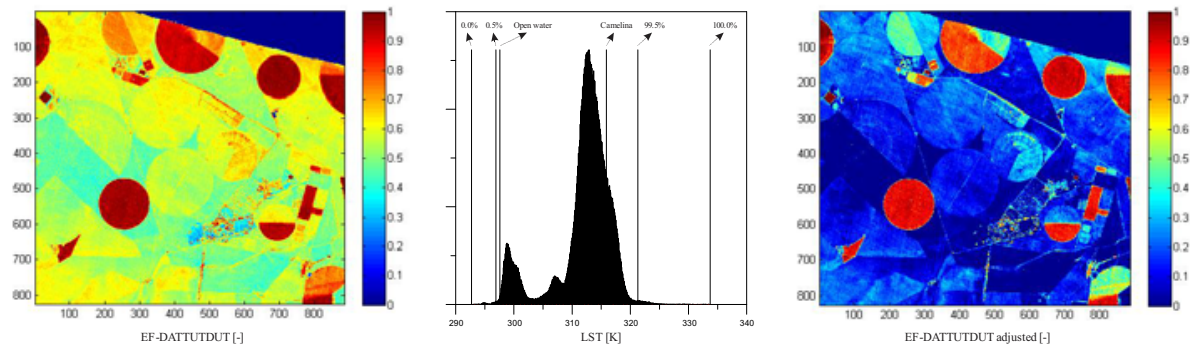

Fig. 4. Influence of end-member selection on model output.

To demonstrate the effect of end-member selection on spatial model results $T_{\min }$ and $T_{\max }$ are selected based on the minimum and maximum LST averaged per landcover unit (Table 3). In the left and right panel of Fig. 4 the model output for $\Lambda$ is shown for the original model run and for the adjusted end-members, respectively, whereas the average results grouped per landcover type are shown in the right-most column of Table 3. A considerable improvement in spatial agreement is seen after this adjustment. With the exception of built-up areas (buildings) and poppy landcover units, the DATTUTDUT model results are comparable to the more physically-based approaches (see Table 3). This indicates that over problematic, i.e., dry and sparsely vegetated, areas model results may improve considerably after adjusting the end-member values based on landcover. A procedure could be developed based on landcover information to ensure proper linking between $T_{\min }$ and $T_{\max }$ and the hydrological extremes (wet and dry conditions), a technique also used in other index-type of models (Kalma et al. 2008). However, in this paper the objective is to demonstrate the utility of a completely automated approach without user adjustments for monitoring evapotranspiration.

\subsection{Temporal model evaluation}

The daily average net radiation from the SEBAL and DATTUTDUT schemes is compared with the ground observations in Fig. 5. Although the procedure used in Gieske and Meijninger (2005) to derive daily average net radiation is not exclusively related to the SEBAL algorithm, for simplicity the results are referred to as SEBAL estimates. For both schemes the $R_{N}$ estimates shown are taken from the pixel at the cotton site, where the weather station is situated. Both models seem to follow the temporal trend and magnitudes of the observations rather well, although SEBAL shows slightly higher estimates at the beginning of the season whereas DATTUDUT shows slightly higher values towards the end of the season. The overall general agreement is supported by the relatively low RMSD value between modeled 


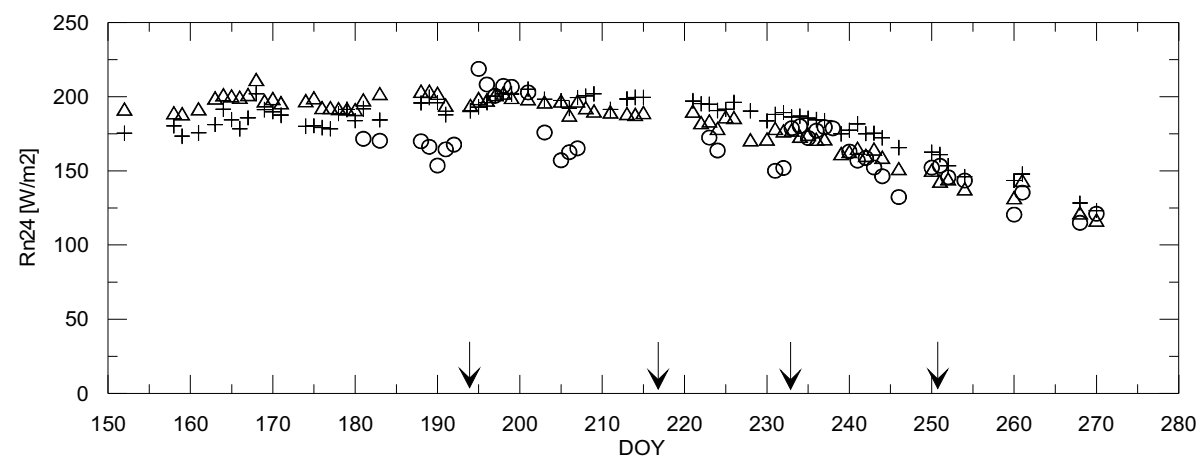

Fig. 5. Daily values of net radiation for the cotton site plotted against day number. AVHRR-DATTUTDUT values $(+)$ and SEBAL estimates $(\Delta)$ are compared with those determined with the weather station $(\circ)$ on the cotton field.

and measured daily $R_{n}$ which is $\sim 20 \mathrm{~W} \mathrm{~m}^{-2}$ (MAPD $\sim 10 \%$ ), for both the SEBAL and DATTUTDUT algorithms.

Following irrigation, indicated by arrows in Fig. 5, the ground observations show an increase in net radiation, due to a decrease in both albedo and surface temperature. However, this effect is not clearly seen in the satellite approaches where only a minor increase is computed which is slightly more pronounced for the DATTUTDUT estimates.

The turbulent flux observations are areal averages which depend on windspeed, wind direction, and aerodynamic properties of the upwind landscape and can be determined using the so-called footprint calculations (Schmid 1994, Timmermans et al. 2009). Due to the absence of detailed wind direction and wind speed information in the current study the average of a four-pixel window is taken over the cotton site. A similar four-pixel window is taken in the center of the heterogeneous valley in the middle of the scintillometer transect since this is the area contributing the most to the observed signal. In Figure 6, the estimated evaporative fractions from both remote sensing techniques are compared for the homogeneous cotton site and the heterogeneous valley site, Fig. $6 a$ and $b$, respectively. In addition, an inter-comparison of model output of the time evolution of evaporative fraction over the growing season is shown in Fig. $6 \mathrm{c}$ and d. It is clearly seen that correlation in model output for the cotton site is much higher than for the valley site ( $R^{2}$ is 0.915 and 0.054 , respectively). For the valley site there is actually a negative correlation-although it is statistically not significantly different from zero. Over this site, evaporative fraction estimates from SEBAL increase slightly over the season, whereas DATTUTDUT output has a decreasing trend over the season. 

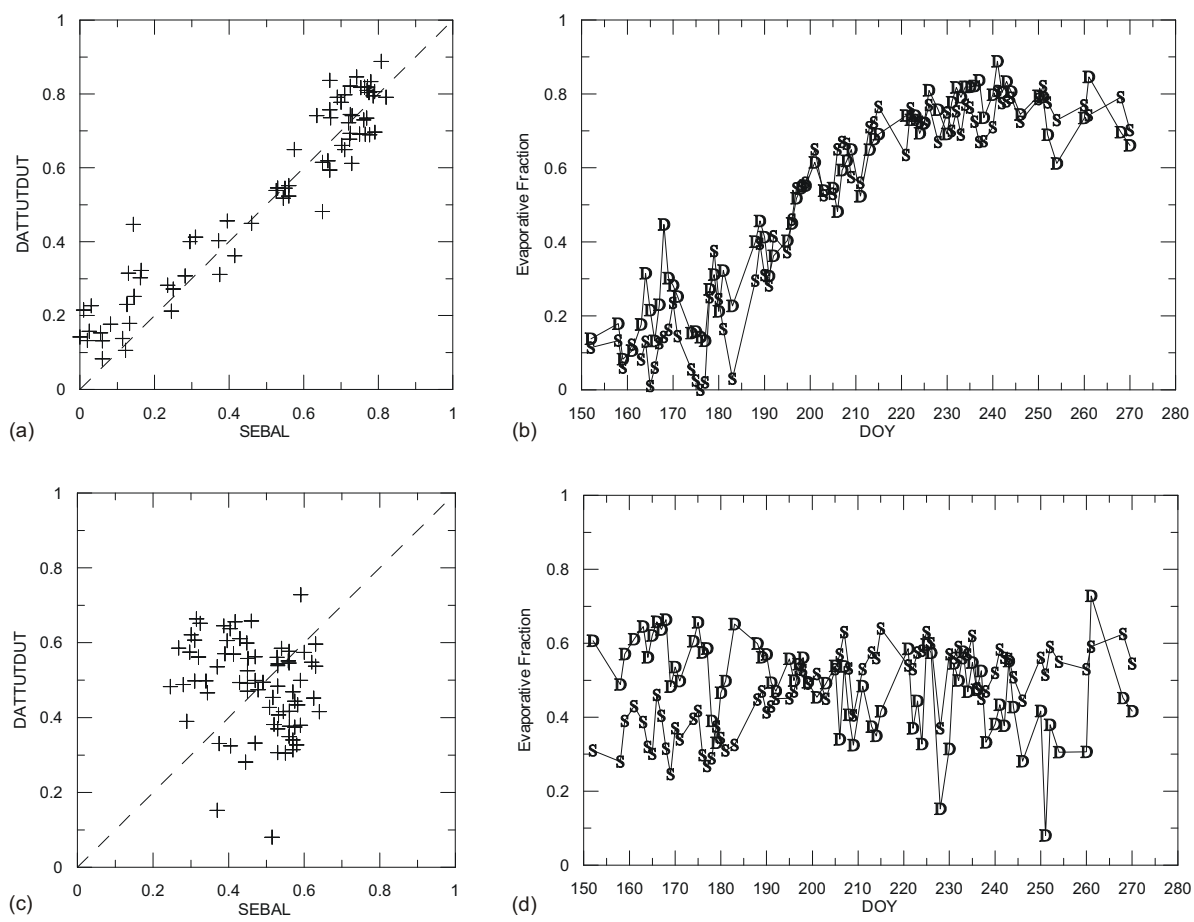

Fig. 6. DATTUTDUT (D-symbol) versus SEBAL (S-symbol) evaporative fraction estimates for the cotton (upper panels) and the valley site (lower panels).

A comparison of model output with observations of daily $E T$, for both methods estimated using Eq. 9, is illustrated for both sites in Fig. 7. In Figure 7a-c results are displayed for the cotton site and in Fig. 7d-f, results are shown for the valley location. Following Gieske and Meijninger (2005) the LAS data is combined with the AVHRR-derived daily $R_{N}$ estimates to derive daily amounts of ET from Eq. 9.

In the model-measurement comparisons of daily ET displayed in Fig. 7, both models tend to underestimate the ground observations for both sites, with SEBAL output showing significantly greater bias. This effect is particularly evident in the beginning of the season, as seen in Fig. 7c and $\mathrm{f}$ and even more clear in Fig. $6 b$ and $d$ where DATTUTDUT estimates of evaporative fraction are higher than those of SEBAL. The better performance of the DATTUTDAT scheme over the growing season is supported by the difference statistics for the cotton site, which yielded RMSD values of 1.7 and $1.3 \mathrm{~mm} \mathrm{day}^{-1}$ (MAPD values of 35 and 28\%) for SEBAL and DATTUTDUT, respectively. 

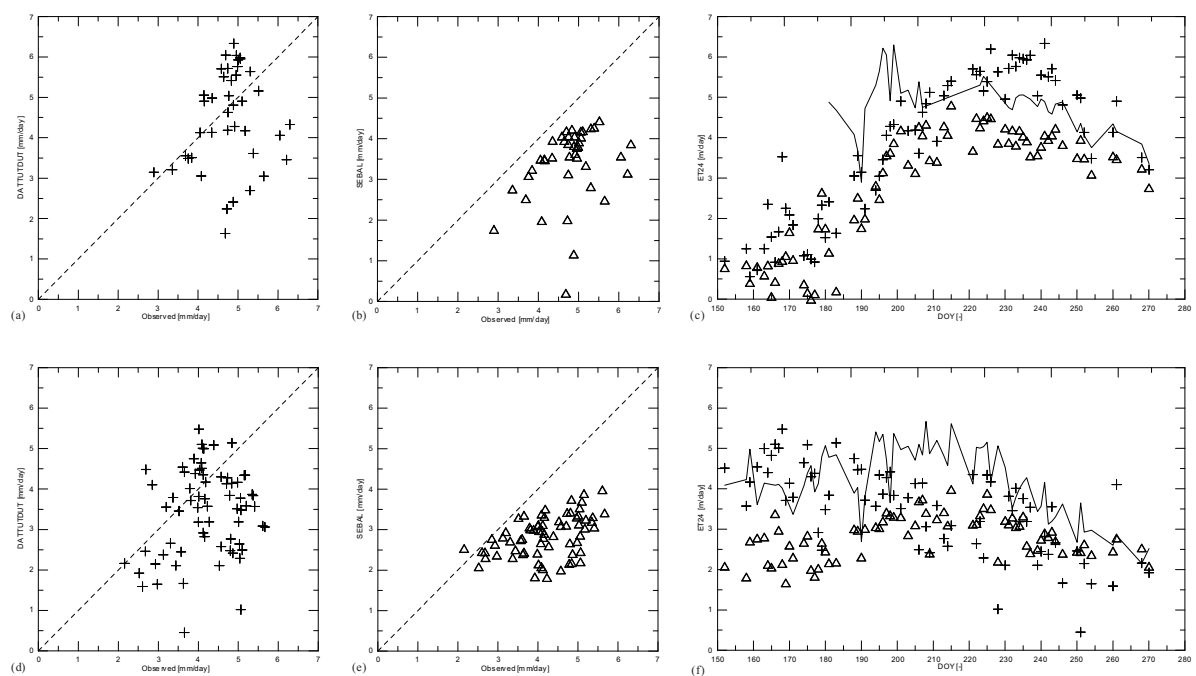

Fig. 7. Daily amounts of evapotranspiration, ET [mm/day], over the cotton (a-c) and valley site (d-f). For panels a, b, d, and f, model results versus observations are illustrated. For panels $\mathrm{c}$ and $\mathrm{f}$, the observations $(-)$ as well as the SEBAL $(\Delta)$ and DATTUTDUT $(+)$ results are plotted temporally over the course of the growing season.

Over the valley site, the RMSD values for SEBAL and DATTUTDUT are rather similar, namely $\sim 1.5 \mathrm{~mm} \mathrm{day}^{-1}$ with MAPD value of $\sim 35 \%$. In Figure $7 \mathrm{f}$, the DATTUTDUT and the ground observations follow a similar temporal trend, but DATTUTDUT slightly underestimates the daily amounts in the second half of the growing season with respect to ground observations. On the other hand, SEBAL estimates show little temporal variation over the season. Since the net radiation estimation from both models is rather similar over the growing season for this site (correlation coefficient $r^{2}$ is equal to 0.8 ), the difference in ET estimates has to originate from the different estimates of the evaporative fraction. Generally, in the second half of the growing season the two methods are in better agreement with the observations, although there is a slight underestimation by both remote sensing-based approaches with respect to the measurements over the valley site.

Cumulative $E T$ values are shown in Fig. 8 for the cotton site as presented by Gieske and Meijninger (2005) using the ground observations and SEBAL output for the monitoring period spanning a rain free period from DOY 150 to 270 (30 May until 28 September 1998). Using a simple water budget, by differencing the total irrigation and percolation provides an independent indication of the cumulative ET in this period. Droogers and Bastiaanssen (2002) reported a total of $545 \mathrm{~mm}$ supplied for irrigation in this period and a 


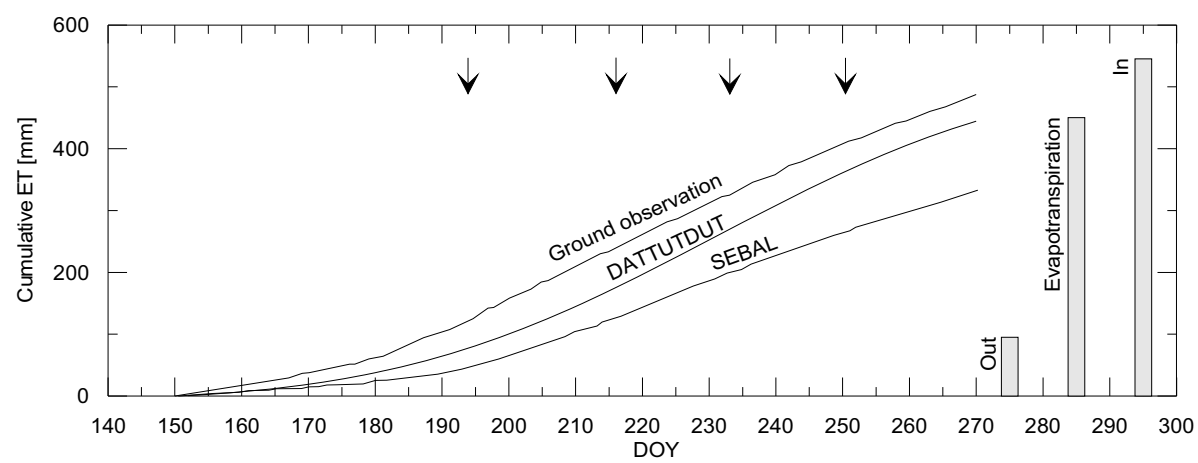

Fig. 8. Cumulative $E T$ values derived from the temperature variance observations and from DATTUTDUT and SEBAL over the irrigated cotton site. The figure also displays the totals resulting from a simple water budget calculation where "In" represents the total amount of irrigation and "Out" is the total outgoing bottom flux or percolation for the monitoring period and the "Evapotranspiration" = In-Out.

yearly percolation of $284 \mathrm{~mm}$, continuously downward throughout the year. Assuming equally distributed percolation over the year yields a total water use for the monitoring period of $452 \mathrm{~mm}$. However, since figures for grape landcover indicated less percolation, and at times even capillary rise during the growing season, this figure might be slightly higher. The components of the simple water budget are also shown in Fig. 8, where "In" represents the total amount of irrigation and "Out" stands for the total outgoing bottom flux or percolation for the monitoring period.

Plotting cumulative ET modulates some of the scatter and errors in daily $E T$, and makes clearer the systematic bias between the models and observations (Gieske and Meijninger 2005). Comparing the two remote sensing models, and the simple water balance method with the ground measurements, yields underestimates of 44, 155 and $38 \mathrm{~mm}$ with DATTUTDUT, SEBAL and simple water balance methods, respectively. Relative to cumulative $E T$ for the monitoring period this yields MAPD values between ET observations and DATTUTDUT, SEBAL, and simple water balance estimates of 9,32 , and $8 \%$, respectively.

The underestimation of ET during the growing season by the remote sensing methods is a concern and needs to be investigated in greater detail. With regard to the trends, it appears that both remote sensing based methods respond fairly well to the start of the growing season (irrigation days are indicated by arrows). However, the DATTUTDUT method yields the greatest rise (slope) during the main irrigation period (roughly from DOY 210 to 250), possibly indicating a better performance under these conditions. 


\section{DISCUSSION}

In a remote sensing model intercomparison study, Timmermans et al. (2007) documented the poor performance in estimating heat fluxes when applying a version of SEBAL over dry and sparsely vegetated conditions. Similarly, an intercomparison study by Choi et al. (2009) over the SMEX/SMACEX'02 study region found significant discrepancies in modeled turbulent heat flux patterns between TSEB and the Mapping EvapoTranspiration at high Resolution using Internalized Calibration (METRIC) approach, a derivative of SEBAL, that were largely correlated with vegetation density. Generally, the largest discrepancies, primarily a bias in $H$, between these two models occurred in areas with partial vegetation cover. A similar result is noted in the current study.

The reported disagreement in $R_{N}$ for DATTUTDUT has several reasons which are counter-acting in both the shortwave and the longwave radiation components. Unfortunately, only a limited number of radiation component observations are available for the datasets used. Mainly net radiometers and pyranometers were used to measure $R_{N}$ and $R_{S} \downarrow$ whereas only at a few sites albedo measurements were carried out. Concerning the incoming radiation components, the SEBAL and TSEB algorithms use observations of $R_{S}$, whereas DATTUTDUT assumes a constant transmissivity of 0.7 [ - ] in combination with the exo-atmospheric radiation. The average observed transmissivity for the dataset used was 0.79 [-], yielding an average underestimation around $70 \mathrm{~W} \mathrm{~m}^{-2}$ at the average observed $R_{S} \downarrow$ (i.e., $800 \mathrm{~W} \mathrm{~m}^{-2}$ ). On the other hand, using the set transmissivity to derive an atmospheric emissivity using Eq. 6 yields an over-estimation of some $40 \mathrm{~W} \mathrm{~m}^{-2}$ at an average air temperature of around $300 \mathrm{~K}$ for $R_{L} \downarrow$. With respect to the outgoing radiation components, the DATTUTDUT assumptions also generally result in compensating errors. At the few sites where albedo was measured, 6 in total, the TSEB and SEBAL algorithms showed a near-perfect fit with the observations, whereas the DATTUTDUT scheme showed an under-estimation of around $50 \%$. With average values of $R_{S} \downarrow$ and albedo (i.e., $0.2[-]$ ) this yields an over-estimation of $R_{N}$ around $80 \mathrm{~W} \mathrm{~m}^{-2}$. Using a surface emissivity equal to unity with an average high-end surface temperature of around $315 \mathrm{~K}$, an over-estimation of $R_{L}^{\uparrow}$ of about $30 \mathrm{~W} \mathrm{~m}^{-2}$ is noted as compared to using typical bare soil emissivities of 0.95 [-]. Although the average net effect is rather limited, around $20 \mathrm{~W} \mathrm{~m}^{-2}$, largest deviations are noted over hot and dry, sparsely vegetated areas. The incoming radiation components are spatially rather homogeneous but at these dry and sparsely vegetated locations the outgoing radiation components are largest. Therefore, under these circumstances, the DATTUTDUT assumptions of unity surface emissivity and linearity between albedo and temperature produce the largest discrepan- 
cies, i.e., an under-estimation, with both the SEBAL and TSEB output as well as with the observations of $R_{N}$.

As mentioned before, a large part of the discrepancy between the modelled and observed values for $G$ is caused by the direct linkage of $G$ with $R_{N}$. A second reason might be an over-simplification of the relation between $G$ and $R_{N}$ used here; see Eq. 7. Assuming the surface temperature is the only indicator that determines how much radiation is penetrating through the vegetation and reaching the soil is not only an oversimplified metric for determining vegetation density but also gives erroneous results under wet surface soil moisture conditions. Consequently, the standard deviation of the predicted $G$ values is considerably lower than that of the observations, although to a lesser extent this is also noted for TSEB and SEBAL. A relatively flat response and under-estimation for soil heat fluxes is a phenomenon seen more often in remote sensing-based SVAT models (Jacob et al. 2002, Timmermans et al. 2007). This, despite attempts to incorporate the dynamic behavior of the $G$ ratio by either introducing a time-dependence (Kustas et al. 1998, Santanello and Freidl 2003), or by incorporating the surface temperature in a semi-empirical manner (Bastiaanssen et al. 1998).

Concerning the turbulent fluxes, in past studies, for midday convective conditions, typically an RMSD-value between modeled and measured turbulent heat fluxes of approximately $50 \mathrm{~W} \mathrm{~m}^{-2}$ or less and/or MAPD-value of less than 20\% is considered acceptable agreement (Hanna and Chang 1992, Kalma et al. 2008, Kustas and Norman 2000, Twine et al. 2000). This level of agreement considers the fact that energy closure problems (Oncley et al. 2002) and uncertainties in footprint analysis (Foken and Leclerc 2004, Hoedjes et al. 2007, Timmermans et al. 2009) cause uncertainties in $H$ and $\lambda E$ tower measurements that are often similar in magnitude to modelmeasurement differences of $\sim 50 \mathrm{~W} \mathrm{~m}^{-2}$. In Table 2, the difference statistics for the TSEB scheme meet these error criteria, while the errors using DATTUTDUT and SEBAL do not. Nevertheless, the simpler schemes requiring less input data and expertise to run (particularly DATTUTDUT) still give useful $H$ and $\lambda E$ estimates except under dry and sparsely vegetated conditions.

The DATTUTDUT approach uses the evaporative fraction concept in combination with daily $R_{N}$ estimates to produce daily $E T$ values. Therefore the absolute discrepancies in $H$ and $\lambda E$ become less critical, which was also noted in the temporal evaluation of the model. The general trend of observed daily ET values over a growing season for two sites in Turkey is reproduced reasonably well, with DATTUTDUT outperforming the SEBAL scheme.

Root Mean Squared Differences between both satellite-based model estimates and observed daily $R_{N}$ over the growing season were mainly caused by the difference in the scale of observations. The net radiation, measured at 
$2.5 \mathrm{~m}$, was representative at the local or patch scale which are on the order of $150 \mathrm{~m}^{2}$. Although the observation site, which was located in a $300 \times 500 \mathrm{~m}^{2}$ cotton field surrounded by other cotton fields, was homogeneous at the AVHRR resolution with respect to land use, the irrigation pattern varied for each farm (Kite and Droogers 2000). This may explain the more smooth response of the satellite-based approaches for net radiation as compared to the ground observations, which were more strongly influenced by irrigation activity.

Despite the simplification of using a constant atmospheric transmissivity over the growing season, the RMSD values for daily $R_{N}$ were only around $20 \mathrm{~W} \mathrm{~m}^{-2}$. Substituting a variable transmissivity over the season, using Eq. 5, did not significantly improve the DATTUTDUT results. An average increase over the season of $3 \%$ in $R_{N}$ was noted, which was mainly caused by deviations toward the end of the season, which were up to a maximum of $8.5 \%$. Over the cotton site this caused a deterioration in RMSD for daily ET from 1.31 to $1.38 \mathrm{~mm}^{-1 a y}{ }^{-1}$ and for the valley site a slight improvement from 1.45 to $1.41 \mathrm{~mm}$ day $^{-1}$.

A potentially larger source of error in both SEBAL and DATTUTDUT is the selection of the extreme pixels, as also noted in the spatial intercomparison. According to Meijninger (2003), the selection of the dry pixels in the initial, non-irrigated period, may be tenuous due to the difficulty in finding representative dry pixels under regionally humid and wet surface conditions that typically exist in the early period of the growing season here. Under such circumstances, selecting dry pixels that in reality do not represent the true dry extreme, and hence the "dry pixel" $E T>0$, causes a bias (underestimation of $E T$ ) for other pixels in the scene as these techniques force more of the available energy to be partitioned into $H$ instead of $L E$. There is slightly less of a bias issue or underestimation for the DATTUTDUT scheme because the selection of the dry pixel is automated and always is the highest temperature value in the image.

An example of the issue in assigning wet and dry pixel temperatures is provided in Fig. 9, where two-dimensional scatterplots of surface temperature versus albedo are shown for a day early in the season (DOY 167) and one later in the growing season (DOY 196) accompanied by the frequency distribution of the surface temperature. The solid lines indicate the wet and dry pixel temperature automatically selected by the DATTUTDUT algorithm, where the shaded area in the frequency distribution represents $0.5 \%$ of the total area determining the wet pixel selection. The dotted lines indicate the area where the dry pixel is most likely to be selected following the standard SEBAL procedure. Note that selecting a proper dry pixel for the SEBAL procedure from the scatterplot in Fig. $9 \mathrm{~b}$ is more straightforward than in the case of Fig. 9a. 

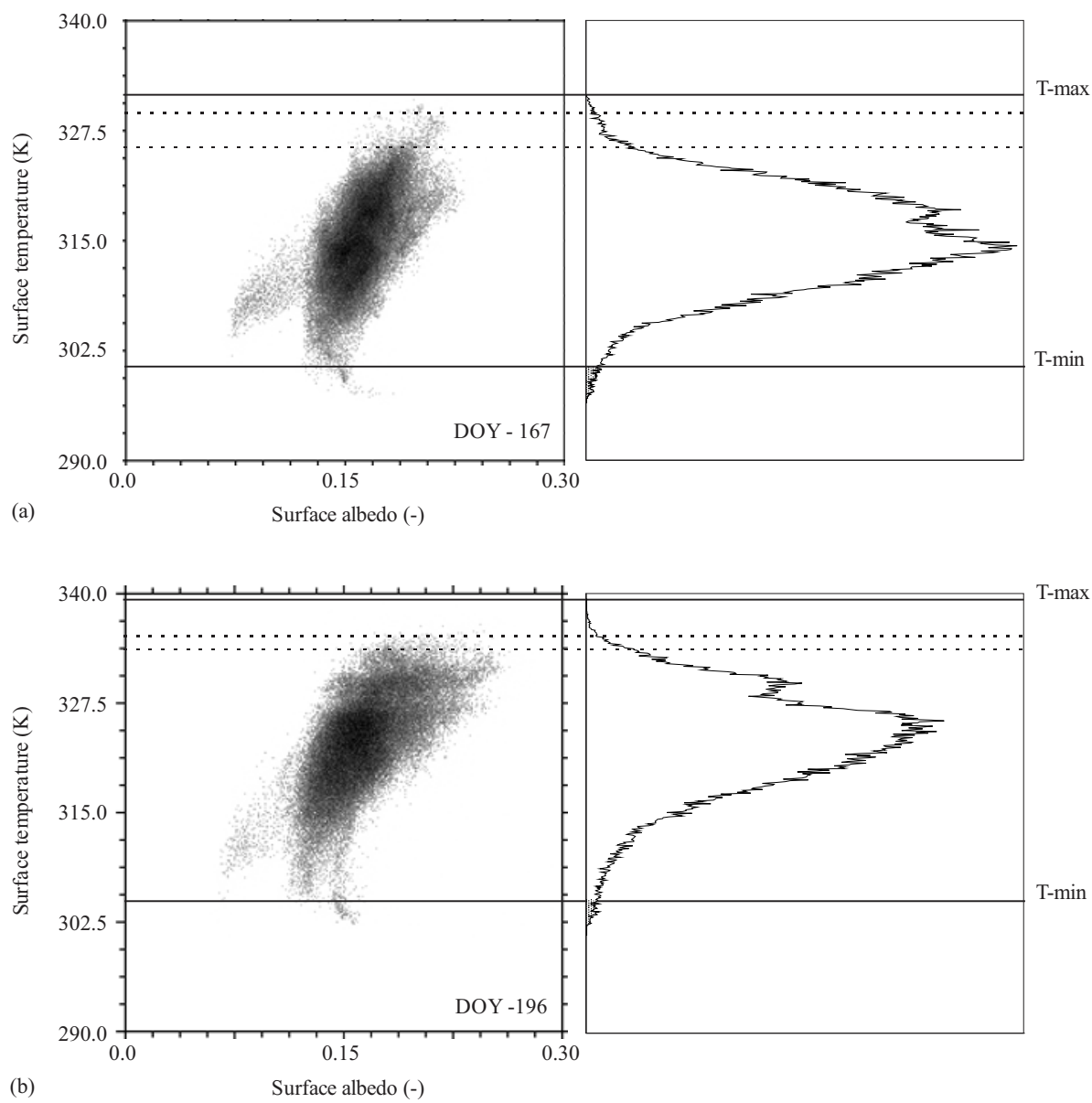

Fig. 9. Two-dimensional scatterplots of surface temperature versus surface albedo for an early season day (DOY 167) and a mid-season day (DOY 196) image. The solid lines indicate the wet a $\left(T_{\min }\right)$ and dry $\left(T_{\max }\right)$ pixel temperature automatically selected by the DATTUTDUT algorithm, where the shaded area in the frequency distribution represents $0.5 \%$ of the total area determining the wet pixel selection. The dotted lines indicate the likely $T_{\max }$ values for the dry pixel following the standard SEBAL procedure.

Although this procedure is automated in the case of DATTUTDUT, this does point out a limitation of these types of schemes, namely that a wet and a dry pixel are required within the scene. The existence of wet and dry pixels may not be present, and also will be pixel-resolution dependent, as also illustrated in Section 3.3.

With respect to daily $E T$, for the cotton site both satellite methods and the observations showed a similar behavior over the study period; see 
Fig. 7c. During the first half of the season, observations yield the highest $E T$ values, SEBAL the lowest and with the DATTUTDUT estimates somewhere in between. Apart from the temperature selection procedure this may be caused by a fairly large negative soil heat flux observed during the first days after irrigation. Since the satellite based methods assume a negligible daily soil heat flux, both turbulent fluxes will be under-estimated, since daily available energy $\left(R n_{24}-G_{24}\right)$ is under-estimated. From roughly DOY 225 to 245 DATTUTDUT is overestimating and SEBAL is underestimating the observed ET by similar magnitudes. There is no obvious explanation for this result. From DOY 245 until 270, which is the end of the growing season, DATTUTDUT is in close agreement with the observation, whereas SEBAL slightly underestimates the daily $E T$.

The reported RMSD values for daily ET seem rather large, but Kite and Droogers (2000) showed similar discrepancies for two selected days (DOY 177 and 241) using 9 different methods of estimating daily ET. Average ET values over the cotton site for the two days were 3.5 and $4.6 \mathrm{~mm}_{\text {day }}{ }^{-1}$, respectively, whereas standard deviations among the different methods were as high as 1.6 and $1.1 \mathrm{~mm} \mathrm{day}^{-1}$. The ET values from SEBAL and DATTUTDUT for the two days were 0.1 and 0.8 for DOY 177 and 6.3 and 4.1 for DOY 241, respectively. For DOY 241, the two model estimates fall within the variation of other methods, but for the start of the season (DOY 177) both models showed an under-estimation, which is attributed to the assumption of negligible soil heat flux described above. The average $E T$ value computed by Kite and Droogers (2000) for the valley site was $\sim 4.0 \mathrm{~mm} \mathrm{day}^{-1}$ with standard deviation of $1.0 \mathrm{~mm} \mathrm{day}^{-1}$ for both DOY 177 and 241. Daily $E T$ from SEBAL and DATTUTDUT for these days are 1.8 and $4.4 \mathrm{~mm}$ for DOY 177 and 3.0 and $2.8 \mathrm{~mm}$ for DOY 241. Again for DOY 241 both models fall within the variation of other methods while there is a slight underestimation for DOY 177.

Model validation is usually performed using a handful of tower-based flux observations which are usually situated in homogeneous sites and as such typically are not representative of extreme or unique conditions. As such, assessing model performance with measurements at several selected sites does not guarantee that a model will provide reliable flux estimates over the whole scene, particularly in heterogeneous landscapes (Timmermans et al. 2007). Therefore, a spatial model evaluation was carried out over the Barrax site. Sensitivity to the selection of proper temperature endmembers was demonstrated and results suggested a procedure might be developed to ensure proper linking between $T_{\min }$ and $T_{\max }$ and the hydrologic extremes. However, forested areas can have high sensible heat fluxes and low surface-air temperature difference due to a very low aerodynamic resistance. This situation will not be properly accommodated by a model that 
does not parameterize aerodynamic roughness effects on the flux-gradient relationship. To investigate model performance and assumptions under such conditions requires a study described in Norman et al. (2006) that involves an inter-comparison and analysis of fluxes generated by different remote sensing-based modeling approaches in comparison to detailed simulations for a full range in hydrologic and aerodynamic conditions using a complex multi-source soil-plant-environment model. Simulations from a detailed SVAT from a study evaluating the effects of sub-pixel variability by Kustas and Norman (2000) could serve as a test case. However, this is beyond the scope of the current contribution, which is focused demonstrating the model utility covering a wide range in fractional vegetation cover, soil moisture, and meteorological conditions.

In summary, the simple schemes requiring less input data and expertise to run (particularly DATTUTDUT) still give useful $H$ and $\lambda E$ estimates except under very dry and sparsely vegetated conditions. The difference in model performance between TSEB, SEBAL, and DATTUTDUT over such locations may have different reasons, such as the explicit use of climatic data in TSEB and SEBAL and not in DATTUTDUT, or the way aerodynamic properties are prescribed, one-source for SEBAL, two-source for TSEB, and not for DATTUTDUT, effects which have been examined by many others (Choi et al. 2009, French et al. 2005b, Timmermans et al. 2007). However, since the discrepancies with local flux observations for DATTUTDUT mainly occur over dry and sparsely vegetated areas, we firmly believe the underestimation of $R_{N}$ combined with the selection of $T_{\max }$ using high resolution imagery, at these locations are the main reasons. At these locations the latent heat flux is set to zero. Would the estimate of available energy have been higher at these locations, the majority of the available energy would have been attributed to the sensible heat flux, which would reduce the evaporative fraction.

\section{CONCLUDING REMARKS}

In this study a remote sensing-based framework (DATTUTDUT) is developed for the automated estimation of surface energy balance components from remotely sensed radiometric surface temperature only. The method can be used to derive a spatially distributed map of actual evapotranspiration over large heterogeneous areas, provided that hydrologic extremes or wet and dry conditions are present.

Maps of surface energy balance components using the current approach were compared to ground observations and two other more complex remote sensing-based land surface models that have been validated numerous times in the literature. The inter-comparisons were made using large scale field experimental data collected over heterogeneous landscapes under a wide 
range of environmental conditions. This simple and fully automated scheme was shown to provide estimates of the available energy (net radiation less soil heat flux) and turbulent (sensible and latent heat) fluxes comparable to these established and more complex remote sensing-based schemes, but only under less extreme and heterogeneous environmental conditions. Discrepancies with observations were significant using either SEBAL, version of Bastiaanssen et al. (1998), or DATTUTDUT approaches under dry sparsely vegetated areas.

The DATTUTDUT scheme was also applied to an irrigated site for the purposes of evaluating its utility for seasonal monitoring of crop water use. The scheme provided estimates of daily ET that generally underestimate the observations with significant scatter. Clearly there are environmental conditions (both hydrometeorological and land cover/land use) that limit the utility of both the DATTUTDUT and SEBAL schemes. For example, early in the growing season wet and dry pixels are difficult to identify and when the region is under water stressed conditions, this procedure is also less reliable unless land use is considered in defining $T_{\max }$ (see Table 3). Moreover, the DATTUTDUT scheme cannot account for the effect of significant variation of aerodynamic properties of the landscape, which can have a dramatic impact on the flux-gradient relationship (Norman et al. 2006). However, given the simplicity of the algorithm and its ease of use, the proposed model has utility in identifying areas of high and low water use even if the ET magnitudes are error-prone (see Fig. 3) and therefore could be an operational tool for rapid monitoring of relative water use or plant stress conditions in regions having little ground information. Once such areas of relatively low and high ET are identified, more physically-based models such as ALEXI/ DisALEXI (Anderson et al. 2011) could be run to more reliably quantify the $E T /$ stress conditions.

To gain a greater sense of the level of uncertainty in ET mapping and monitoring using the current approach, model inter-comparison studies of the type conducted by Timmermans et al. (2007) between the DATTUTDUT scheme and more established remote-sensing based approaches, such as ALEXI/DisALEXI and SEBAL but also for other simple index methods such as S-SEBI and SSEBop, are planned for a variety of landscapes containing a wide range in land use/vegetation cover and environmental conditions.

Acknowledgements. Funding from NASA Interdisciplinary Research Program in Earth Sciences, EOS/Land Surface Hydrology Program and the Terrestrial Hydrology Program as well as USDA-ARS funding made possible the experimental data sets from Monsoon'90, SGP'97, and SMACEX'02, respectively. Funding from the European Community's 7th 
Framework Programme (FP7/2008-2013) under EUFAR contract no. 227159, Cost Action ES0903-EUROSPEC and ESA Grant $\mathrm{D} / \mathrm{EOP} / \mathrm{rp} / 2012 / 48$ made possible the experimental dataset from the REFLEX'12 Campaign. We would like to thank Dr. Wouter Meijninger and Dr. Ambro Gieske for providing the Gediz data, which made it possible to conduct this study. We also thank Dr. Henk de Bruin and Dr. Martha Anderson for their critical and helpful comments and suggestions. USDA is an equal opportunity provider and employer.

\section{References}

Anderson, M.C., J.M. Norman, G.R. Diak, W.P. Kustas, and J.R. Mecikalski (1997), A two-source time-integrated model for estimating surface fluxes using thermal infrared remote sensing, Remote Sens. Environ. 60, 2, 195-216, DOI: $10.1016 / \mathrm{S} 0034-4257(96) 00215-5$.

Anderson, M.C., J.M. Norman, W.P. Kustas, F. Li, J.H. Prueger, and J.R. Mecikalski (2005), Effects of vegetation clumping on two-source model estimates of surface energy fluxes from an agricultural landscape during SMACEX, J. Hydrometeor. 6, 6, 892-909, DOI: 10.1175/JHM465.1.

Anderson, M.C., W.P. Kustas, and J.M. Norman (2007), Upscaling flux observations from local to continental scales using thermal remote sensing, Agron. J. 99, 1, 240-254, DOI: 10.2134/agronj2005.0096S.

Anderson, M.C., W.P. Kustas, J.M. Norman, C.R. Hain, J.R. Mecikalski, L. Schultz, M.P. González-Dugo, C. Cammalleri, G. d'Urso, A. Pimstein, and F. Gao (2011), Mapping daily evapotranspiration at field to continental scales using geostationary and polar orbiting satellite imagery, Hydrol. Earth Syst. Sci. 15, 223-239, DOI: 10.5194/hess-15-223-2011.

Andreu, A., W.J. Timmermans, D. Skokovic, and M.P. Gonzalez-Dugo (2015), Influence of component temperature derivation from dual angle thermal infrared observations on TSEB flux estimates over an irrigated vineyard, Acta Geophys. 63, 6, 1540-1570, DOI: 10.1515/acgeo-2015-0037 (this issue).

Bastiaanssen, W.G.M. (1995), Regionalization of surface flux densities and moisture indicators in composite terrain: a remote sensing approach under clear skies in Mediterranean climates, Ph.D. Thesis, Wageningen Agricultural University, Wageningen, The Netherlands, $273 \mathrm{pp}$.

Bastiaanssen, W.G.M., M. Menenti, R.A. Feddes, and A.A.M. Holtslag (1998), A remote sensing surface energy balance algorithm for land (SEBAL). 1. Formulation, J. Hydrol. 212-213, 198-212, DOI: 10.1016/S0022-1694 (98)00253-4.

Bateni, S.M., D. Entekhabi, S. Margulis, F. Castelli, and L. Kergoat (2014), Coupled estimation of surface heat fluxes and vegetation dynamics from remotely 
sensed land surface temperature and fraction of photosynthetically active radiation, Water Resour. Res. 50, 11, 8420-8440, DOI: 10.1002/ 2013 WR014573.

Brutsaert, W. (1982), Evaporation into the Atmosphere. Theory, History, and Applications, Reidel, Dordrecht, 299 pp.

Brutsaert, W., and D. Chen (1996), Diurnal variation of surface fluxes during thorough drying (or severe drought) of natural prairie, Water Resour. Res. 32, 7, 2013-2019, DOI: 10.1029/96WR00995.

Burridge, D.M., and A.J. Gadd (1974), The Meteorological Office operational 10level numerical weather prediction model (December 1974), Tech. Notes 12 and 48, British Meteorological Office, Bracknell, England, 57 pp.

Cammalleri, C., M.C. Anderson, and W.P. Kustas (2014), Upscaling of evapotranspiration fluxes from instantaneous to daytime scales for thermal remote sensing applications, Hydrol. Earth Syst. Sci. 18, 1885-1894, DOI: 10.5194/ hess-18-1885-2014.

Campbell, G.S., and J.M. Norman (1998), An Introduction to Environmental Biophysics, 2nd ed., Springer, New York, 286 pp., DOI: 10.1007/978-14612-1626-1.

Carlson, T.N., and D.A. Ripley (1997), On the relation between NDVI, fractional vegetation cover, and leaf area index, Remote Sens. Environ. 62, 3, 241252, DOI: 10.1016/S0034-4257(97)00104-1.

Chehbouni, A., J.C.B. Hoedjes, J.-C. Rodriguez, C.J. Watts, J. Garatuza, F. Jacob, and Y.H. Kerr (2008), Using remotely sensed data to estimate areaaveraged daily surface fluxes over a semi-arid mixed agricultural land, $A g r$. Forest Meteorol. 148, 3, 330-342, DOI: 10.1016/j.agrformet.2007.09.014.

Choi, M., W.P. Kustas, M.C. Anderson, R.G. Allen, F. Li, and J.H. Kjaersgaard (2009), An intercomparison of three remote sensing-based surface energy balance algorithms over a corn and soybean production region (Iowa, U.S.) during SMACEX, Agr. Forest Meteorol. 149, 12, 2082-2097, DOI: 10.1016/j.agrformet.2009.07.002.

Choudhury, B.J. (1987), Relationships between vegetation indices, radiation absorption, and net photosynthesis evaluated by a sensitivity analysis, Remote Sens. Environ. 22, 2, 209-233, DOI: 10.1016/0034-4257(87)90059-9.

Choudhury, B.J., N.U. Ahmed, S.B. Idso, R.J. Reginato, and C.S.T. Daughtry (1994), Relations between evaporation coefficients and vegetation indices studied by model simulations, Remote. Sens. Environ. 50, 1, 1-17, DOI: 10.1016/0034-4257(94)90090-6.

Crago, R.D. (1996), Conservation and variability of the evaporative fraction during the daytime, J. Hydrol. 180, 1-4, 173-194, DOI: 10.1016/0022-1694(95) 02903-6.

de Bruin, H.A.R. (1987), From Penman to Makkink. In: J.C. Hooghart (ed.), "Evaporation and Weather" Proceedings and Information, 25 March 1987, 
Hague, Netherlands, TNO Committee on Hydrological Research, Vol. 39, 5-31.

de Bruin, H.A.R. (1994), Analytic solutions of the equations governing the temperature fluctuation method, Bound-Lay. Meteorol. 68, 4, 427-432, DOI: 10.1007/BF00706800.

de Miguel, E., M. Jiménez, I. Pérez, Ó.G. de la Cámara, F. Muñoz, and J.A. GómezSánchez (2015), AHS and CASI processing for the REFLEX remote sensing campaign: methods and results, Acta Geophys. 63, 6, 1485-1498, DOI: 10.1515/ acgeo-2015-0031 (this issue).

Delogu, E.,G. Boulet, A. Olioso, B. Coudert, J. Chirouze, E. Ceschia, V. le Dantec, O. Marloie, G. Chehbouni, and J.-P. Lagouarde (2012), Reconstruction of temporal variations of evapotranspiration using instantaneous estimates at the time of satellite overpass, Hydrol. Earth Syst Sci. 16, 2995-3010, DOI: 10.5194/hess-16-2995-2012.

Droogers, P., and W. Bastiaanssen (2002), Irrigation performance using hydrological and remote sensing modeling, J. Irrig. Drain. Eng. ASCE 128, 1, 11-18, DOI: 10.1061/(ASCE)0733-9437(2002)128:1(11).

Duffie, J.A., and W.A. Beckman (1991), Solar Engineering of Thermal Processes, 2nd ed., John Wiley \& Sons, New York, 944 pp.

Foken, T., and M.Y. Leclerc (2004), Methods and limitations in validation of footprint models, Agr. Forest Meteorol. 127, 3-4, 223-234, DOI: 10.1016/ j.agrformet.2004.07.015.

French, A.N., T.J. Schmugge, W.P. Kustas, K.L. Brubaker, and J. Prueger (2003), Surface energy fluxes over El Reno, Oklahoma, using high-resolution remotely sensed data, Water Resour. Res. 39, 6, 1164, DOI: 10.1029/ 2002 WR001734.

French, A.N., F. Jacob, M.C. Anderson, W.P. Kustas, W. Timmermans, A. Gieske, Z. Su, H. Su, M.F. McCabe, F. Li, J. Prueger, and N. Brunsell (2005a), Corrigendum to "Surface energy fluxes with the Advanced Spaceborne Thermal Emission and Reflection radiometer (ASTER) at the Iowa 2002 SMACEX site (USA)" [Remote Sensing of Environment 2005 99/1-2; 5565], Remote Sens. Environ. 99, 4, 471, DOI: 10.1016/j.rse.2005.10.001.

French, A.N., F. Jacob, M.C. Anderson, W.P. Kustas, W. Timmermans, A. Gieske, Z. Su, H. Su, M.F. McCabe, F. Li, J. Prueger, and N. Brunsell (2005b), Surface energy fluxes with the Advanced Spaceborne Thermal Emission and Reflection radiometer (ASTER) at the Iowa 2002 SMACEX site (USA), Remote Sens. Environ. 99, 1-2, 55-65, DOI: 10.1016/j.rse.2005. 05.015 .

Garratt, J.R. (1992), The Atmospheric Boundary Layer, Cambridge University Press, Cambridge.

Gentine, P., D. Entekhabi, A. Chehbouni, G. Boulet, and B. Duchemin (2007), Analysis of evaporative fraction diurnal behaviour, Agr. Forest Meteorol. 143, 1-2, 13-29, DOI: 10.1016/j.agrformet.2006.11.002. 
Gieske, A., and W. Meijninger (2005), High density NOAA time series of ET in the Gediz Basin, Turkey, Irrig. Drain. Syst. 19, 3-4, 285-299, DOI: 10.1007/ s10795-005-5191-3.

Goetz, S.J., S.D. Prince, S.N. Goward, M.M. Thawley, and J. Small (1999), Satellite remote sensing of primary production: an improved production efficiency modeling approach, Ecol. Model. 122, 3, 239-255, DOI: 10.1016/S03043800(99)00140-4.

Hanna, S.R., and J.C. Chang (1992), Boundary-layer parameterizations for applied dispersion modeling over urban areas, Bound.-Lay. Meteorol. 58, 3, 229259, DOI: 10.1007/BF02033826.

Hoedjes, J.C.B., A. Chehbouni, J. Ezzahar, R. Escadafal, and H.A.R. de Bruin (2007), Comparison of large aperture scintillometer and eddy covariance measurements: Can thermal infrared data be used to capture footprintinduced differences? J. Hydrometeorol. 8, 2, 144-159, DOI: 10.1175/ JHM561.1.

Humes, K.S., W.P. Kustas, and M.S. Moran (1994), Use of remote sensing and reference site measurements to estimate instantaneous surface energy balance components over a semiarid rangeland watershed, Water Resour. Res. 30, 5, 1363-1373, DOI: 10.1029/93WR03082.

Jackson, R.D., S.B. Idso, R.J. Reginato, and P.J. Pinter Jr. (1981), Canopy temperature as a crop water stress indicator, Water Resour. Res. 17, 4, 1133-1138, DOI: 10.1029/WR017i004p01133.

Jackson, T.J., D.M. le Vine, A.Y. Hsu, A. Oldak, P.J. Starks, C.T. Swift, J.D. Isham, and M. Haken (1999), Soil moisture mapping at regional scales using microwave radiometry: the Southern Great Plains hydrology experiment, IEEE Trans. Geosci. Remote. Sens. 37, 5, 2136-2151, DOI: 10.1109/ 36.789610 .

Jacob, F., A. Olioso, X.F. Gu, Z. Su, and B. Seguin (2002), Mapping surface fluxes using airborne visible, near infrared, thermal infrared remote sensing data and a spatialized surface energy balance model, Agronomie 22, 6, 669-680, DOI: 10.1051/agro:2002053.

Jiang, L., and S. Islam (2001), Estimation of surface evaporation map over Southern Great Plains using remote sensing data, Water Resour. Res. 37, 2, 329-340, DOI: $10.1029 / 2000 W R 900255$.

Kalma, J.D., T.R. McVicar, and M.F. McCabe (2008), Estimating land surface evaporation: A review of methods using remotely sensed surface temperature data, Surv. Geophys. 29, 4-5, 421-469, DOI: 10.1007/s10712008-9037-z.

Kite, G.W., and P. Droogers (2000), Comparing evapotranspiration estimates from satellites, hydrological models and field data, J. Hydrol. 229, 1-2, 3-18, DOI: 10.1016/S0022-1694(99)00195-X. 
Kustas, W.P., and J.M. Norman (1997), A two-source approach for estimating turbulent fluxes using multiple angle thermal infrared observations, Water Resour. Res. 33, 6, 1495-1508, DOI: 10.1029/97WR00704.

Kustas, W.P., and J.M. Norman (1999), Evaluation of soil and vegetation heat flux predictions using a simple two-source model with radiometric temperatures for partial canopy cover, Agr. Forest Meteorol. 94, 1, 13-29, DOI: 10.1016/ S0168-1923(99)00005-2.

Kustas, W.P., and J.M. Norman (2000), Evaluating the effects of subpixel heterogeneity on pixel average fluxes, Remote Sens. Environ. 74, 3, $327-$ 342, DOI: 10.1016/S0034-4257(99)00081-4.

Kustas, W.P., M.S. Moran, K.S. Humes, D.I. Stannard, P.J. Pinter Jr., L.E. Hipps, E. Swiatek, and D.C. Goodrich (1994a), Surface energy balance estimates at local and regional scales using optical remote sensing from an aircraft platform and atmospheric data collected over semiarid rangelands, Water Resour. Res. 30, 5, 1241-1259, DOI: 10.1029/93WR03038.

Kustas, W.P., E.M. Perry, P.C. Doraiswamy, and M.S. Moran (1994b), Using satellite remote sensing (to extrapolate evapotranspiration estimates in time and space over a semiarid Rangeland basin), Remote Sens. Environ. 49, 3, 275-286, DOI: 10.1016/0034-4257(94)90022-1.

Kustas, W.P., X. Zhan, and T.J. Schmugge (1998), Combining optical and microwave remote sensing for mapping energy fluxes in a semiarid watershed, Remote Sens. Environ. 64, 2, 116-131, DOI: 10.1016/S00344257(97)00176-4.

Kustas, W.P., J.L. Hatfield, and J.H. Prueger (2005), The Soil-Moisture-Atmosphere Couopling Experiment (SMACEX): background, hydrometeorological conditions, and preliminary findings, J. Hydrometeorol. 6, 6, 791-804, DOI: $10.1175 / \mathrm{JHM} 456.1$.

Mecikalski, J.R., G.R. Diak, M.C. Anderson, and J.M. Norman (1999), Estimating fluxes on continental scales using remotely sensed data in an atmosphericland exchange model, J. Appl. Meteorol. 38, 9, 1352-1369, DOI: 10.1175/ 1520-0450(1999)038<1352:EFOCSU>2.0.CO;2.

Meijninger, W.M.L. (2003), Surface fluxes over natural landscapes using scintillometry, Ph.D. Thesis, Wageningen University, Wageningen, The Netherlands.

Meijninger, W.M.L., and H.A.R. de Bruin (2000), The sensible heat fluxes over irrigated areas in western Turkey determined with a large aperture scintillometer, J. Hydrol. 229, 1-2, 42-49, DOI: 10.1016/S0022-1694(99) 00197-3.

Menenti, M., and B.J. Choudhury (1993), Parameterization of land surface evaporation by means of location dependant potential evaporation and surface temperature range. In: H.J. Bolle, R.A.Feddes, and J.D. Kalma (eds.), Proc. Int. Symp. "Exchange Processes at the Land surface for a range of space and time scales", 13-16 July 1993, Yokohama, Japan. 
Menenti, M., W.G.M. Bastiaanssen, and D. van Eick (1989), Determination of surface hemispherical reflectance with Thematic Mapper data, Remote Sens. Environ. 28, 327-337, DOI: 10.1016/0034-4257(89)90124-7.

Monteith, J.L., and M.H. Unsworth (1990), Principles of Environmental Physics, Edward Arnold Publishers, London, 291 pp.

Nichols, W.E., and R.H. Cuenca (1993), Evaluation of the evaporative fraction for parameterization of the surface energy balance, Water Resour. Res. 29, 11, 3681-3690, DOI: 10.1029/93WR01958.

Norman, J.M., W.P. Kustas, and K.S. Humes (1995), Source approach for estimating soil and vegetation energy fluxes in observations of directional radiometric surface temperature, Agr. Forest Meteorol. 77, 3-4, 263-293, DOI: 10.1016/ 0168-1923(95)02265-Y.

Norman, J.M., W.P. Kustas, J.H. Prueger, and G.R. Diak (2000), Surface flux estimation using radiometric temperature: A dual-temperature-difference method to minimize measurement errors, Water Resour. Res. 36, 8, 22632274, DOI: 10.1029/2000WR900033.

Norman, J.M., M.C. Anderson, and W.P. Kustas (2006), Are single-source, remotesensing surface-flux models too simple?, AIP Conf. Proc. 852, 170, DOI: 10.1063/1.2349341.

Oncley, S.P., T. Foken, R. Vogt, C. Bernhofer, W. Kohsiek, H. Liu, A. Pitacco, D. Grantz, L. Ribeiro, and T. Weidinger (2002), The energy balance experiment EBEX-2000. In: Proc. 15th Conf. on Boundary Layers and Turbulence, American Meteorological Society (AMS), 15-19 July 2002, Wageningen University, Wageningen, The Netherlands.

Parlange, M.B., W.E. Eichinger, and J.D. Albertson (1995), Regional scale evaporation and the atmospheric boundary layer, Rev. Geophys. 33, 1, 99124, DOI: 10.1029/94RG03112.

Pelgrum, H., and W.G.M. Bastiaanssen (1996), An intercomparison of techniques to determine the area-averaged latent heat flux from individual in situ observations: A remote sensing approach using the European Field Experiment in a Desertification-Threatened Area data, Water Resour. Res. 32, 9, 2775-2786, DOI: 10.1029/96WR01396.

Prihodko, L., and S.N. Goward (1997), Estimation of air temperature from remotely sensed surface observations, Remote Sens. Environ. 60, 3, 335-346, DOI: 10.1016/S0034-4257(96)00216-7.

Prince, S.D., S.J. Goetz, R.O. Dubayah, K.P. Czajkowski, and M. Thawley (1998), Inference of surface and air temperature, atmospheric precipitable water and vapor pressure deficit using Advanced Very High-Resolution Radiometer satellite observations: comparison with field observations, J. Hydrol. 212-213, 230-249, DOI: 10.1016/S0022-1694(98)00210-8.

Prueger, J.H., J.L. Hatfield, T.B. Parkin W.P. Kustas, L.E. Hipps, C.M.U. Neale, J.I. MacPherson, W.E. Eichinger, and D.I. Cooper (2005), Tower and aircraft eddy covariance measurements of water vapor, energy, and carbon 
dioxide fluxes during SMACEX, J. Hydrometeorol. 6, 6, 954-960, DOI: 10.1175/JHM457.1.

Roerink, G.J., Z. Su, and M. Menenti (2000), S-SEBI: A simple remote sensing algorithm to estimate the surface energy balance, Phys. Chem. Earth B 25, 2, 147-157, DOI: 10.1016/S1464-1909(99)00128-8.

Santanello, J.A., and M.A. Friedl (2003), Diurnal covariation in soil heat flux and net radiation, J. Appl. Meteorol. 42, 6, 851-862, DOI: 10.1175/15200450(2003)042<0851:DCISHF> 2.0.CO;2.

Schmid, H.P. (1994), Source areas for scalars and scalar fluxes, Bound.-Lay. Meteorol. 67, 3, 293-318, DOI: 10.1007/BF00713146.

Senay, G.B., S. Bohms, R.K. Singh, P.H. Gowda, N.M. Velpuri, H. Alemu, and J.P. Verdin (2013), Operational evapotranspiration mapping using remote sensing and weather datasets: A new parameterization for the SSEB approach, J. Am. Water Resour. Assoc. 49, 3, 577-591, DOI: 10.1111/jawr. 12057.

Shuttleworth, W.J., R.J. Gurney, A.Y. Hsu, and J.P. Ormsby (1989), FIFE: The variation in energy partition at surface flux sites, IAHS Publ. 186, 67-74.

$\mathrm{Su}$, Z. (2002), The Surface Energy Balance System (SEBS) for estimation of turbulent heat fluxes, Hydrol. Earth Syst. Sci. 6, 1, 85-100, DOI: 10.5194/ hess-6-85-2002.

Tasumi, M., R.G. Allen, and W.G.M. Bastiaanssen (2000), The theoretical basis of SEBAL. In: A. Morse, T.Tasumi, G.A. Richard, and J.K. William (eds.), Application of the SEBAL Methodology for Estimating Consumptive Use of Water and Stream flow Depletion in the Bear River Basin of Idaho through Remote Sensing, Final report, Department of Biological and Agriculture Engineering, University of Idaho, Moscow, USA, 46-69.

Timmermans, W.J., W.P. Kustas, M.C. Anderson, and A.N. French (2007), An intercomparison of the Surface Energy Balance Algorithm for Land (SEBAL) and the Two-Source Energy Balance (TSEB) modeling schemes, Remote Sens. Environ. 108, 4, 369-384, DOI: 10.1016/j.rse.2006.11.028.

Timmermans, W.J., G. Bertoldi, J.D. Albertson, A. Olioso, Z. Su, and A.S.M. Gieske (2008), Accounting for atmospheric boundary layer variability on flux estimation from RS observations, Int. J. Remote Sens. 29, 17-18, 52755290, DOI: 10.1080/01431160802036383.

Timmermans, W.J., Z. Su, and A. Olioso (2009), Footprint issues in scintillometry over heterogeneous landscapes, Hydrol. Earth Syst. Sci. 13, 2179-2190, DOI: 10.5194/hess-13-2179-2009.

Timmermans, W.J., C. van der Tol, J. Timmermans, M. Ucer, X. Chen, L. Alonso, J. Moreno, A. Carrara, R. Lopez, F. de la Cruz Tercero, H.L. Corcoles, E. de Miguel, J.A.G. Sanchez, I. Pérez, B. Franch, J.-C.J. Munoz, D. Skokovic, J. Sobrino, G. Soria, A. MacArthur, L. Vescovo, I. Reusen, A. Andreu, A. Burkart, C. Cilia, S. Contreras, C. Corbari, J.F. Calleja, R. Guzinski, C. Hellmann, I. Herrmann, G. Kerr, A.-L. Lazar, B. Leutner, 
G. Mendiguren, S. Nasilowska, H. Nieto, J. Pachego-Labrador, S. Pulanekar, R. Raj, A. Schikling, B. Siegmann, S. von Bueren, and Z.B. Su (2015), An overview of the Regional Experiments For Land-atmosphere Exchanges 2012 (REFLEX 2012) campaign, Acta Geophys. 63, 6, 1465-1484, DOI: 10.2478/s11600-014-0254-1 (this issue).

Twine, T.E., W.P. Kustas, J.M. Norman, D.R. Cook, P.R. Houser, T.P. Meyers, J.H. Prueger, P.J. Starks, and M.L. Wesely (2000), Correcting eddycovariance flux underestimates over a grassland, Agr. Forest Meteorol. 103, 3, 279-300, DOI: 10.1016/S0168-1923(00)00123-4.

van der Tol, C., W.J. Timmermans, C. Corbari, A. Carrara, J. Timmermans, and Z. Su (2014), An analysis of turbulent heat fluxes and the energy balance during the REFLEX campaign, Acta Geophys. 63, 6, 1516-1539, DOI: 10.1515/acgeo-2015-0061 (this issue).

Willmott, C.J. (1984), On the evaluation of model performance in physical geography. In: G.L. Gaile and C.J. Willmott (eds.), Spatial Statistics and Models, Theory and Decision Library, Vol. 40, Reidel Publ., Boston, 443460.

Zhan, X., W.P. Kustas, and K.S. Humes (1996), An intercomparison study on models of sensible heat flux over partial canopy surfaces with remotely sensed surface temperature, Remote Sens. Environ. 58, 3, 242-256, DOI: 10.1016/S0034-4257(96)00049-1.

Received 13 August 2014

Received in revised form 13 March 2015

Accepted 10 April 2015 